\title{
Human Cardiac Stem Cells Isolated from Atrial Appendages Stably Express c-kit
}

\author{
Jia-Qiang He, Duc Minh Vu, Greg Hunt, Atul Chugh, Aruni Bhatnagar, Roberto Bolli*
}

Institute of Molecular Cardiology, University of Louisville, Louisville, Kentucky, United States of America

\begin{abstract}
The in vivo studies of myocardial infarct using c-kit ${ }^{+} / \mathrm{Lin}^{-}$cardiac stem cells (CSCs) are still in the early stage with margin or no beneficial effects for cardiac function. One of the potential reasons may be related to the absence of fully understanding the properties of these cells both in vitro and in vivo. In the present study, we aimed to systematically examine how CSCs adapted to in vitro cell processes and whether there is any cell contamination after long-term culture. Human CSCs were enzymatically isolated from the atrial appendages of patients. The fixed tissue sections, freshly isolated or cultured CSCs

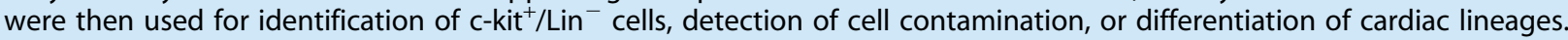
By specific antibody staining, we demonstrated that tissue sections from atrial appendages contained less than $0.036 \% \mathrm{c}-$ $\mathrm{kit}^{+} / \mathrm{Lin}^{-}$cells. For the first time, we noted that without magnetic activated cell sorting (MACS), the percentages of c-kit ${ }^{+} /$ $\mathrm{Lin}^{-}$cells gradually increased up to $\sim 40 \%$ during continuously culture between passage 2 to 8 , but could not exceed $>80 \%$ unless c-kit MACS was carried out. The resulting c-kit ${ }^{+} / \mathrm{Lin}^{-}$cells were negative for CD34, CD45, CD133, and Lin markers, but positive for KDR and CD31 in few patients after c-kit MACS. Lin depletion seemed unnecessary for enrichment of c-kit ${ }^{+} /$Lin $^{-}$ cell population. Following induced differentiation, c-kit ${ }^{+} / \mathrm{Lin}^{-}$CSCs demonstrated strong differentiation towards cardiomyocytes but less towards smooth and endothelial cells. We concluded that by using an enzymatic dissociation method, a large number, or higher percentage, of relative pure human CSCs with stable expression of c-kit ${ }^{+}$could be obtained from atrial appendage specimens within $\sim 4$ weeks following c-kit MACS without Lin depletion. This simple but cost-effective approach can be used to obtain enough numbers of stably-expressed c-kit ${ }^{+} /$Lin $^{-}$cells for clinical trials in repairing myocardial infarction.
\end{abstract}

Citation: He J-Q, Vu DM, Hunt G, Chugh A, Bhatnagar A, et al. (2011) Human Cardiac Stem Cells Isolated from Atrial Appendages Stably Express c-kit. PLoS ONE 6(11): e27719. doi:10.1371/journal.pone.0027719

Editor: Marcello Rota, Brigham \& Women's Hospital - Harvard Medical School, United States of America

Received October 12, 2011; Accepted October 23, 2011; Published November 28, 2011

Copyright: (C) $2011 \mathrm{He}$ et al. This is an open-access article distributed under the terms of the Creative Commons Attribution License, which permits unrestricted use, distribution, and reproduction in any medium, provided the original author and source are credited.

Funding: This work was supported by grants from the National Institutes of Health 5P20RR024489 (to AB/JQH) and 5P01HL078825 (to RB). The funders had no role in study design, data collection and analysis, decision to publish, or preparation of the manuscript.

Competing Interests: The authors have declared that no competing interests exist.

*E-mail: rbolli@louisville.edu

\section{Introduction}

It is a long-held belief that mammalian cardiomyocytes withdraw from the cell cycle during the perinatal period and that the mammalian heart is a terminal post-mitotic organ incapable of selfregeneration after myocardial injury. However, this paradigm has been challenged by the work of Beltrami and colleagues [1] who for the first time, discovered specialized cells within the heart tissue expressing stem cell markers (c-kit, Sca-1, and MDR1). These cells, termed adult cardiac stem cells (CSCs), are capable of fulfilling the criteria for stem cells including self-renewal, clonogenicity, and multipotency. To date, at least 5 different types of CSCs, including the $\mathrm{c}-\mathrm{kit}^{+} / \mathrm{Lin}^{-}$cells $[1,2]$; the Sca- ${ }^{+}$cells $[3,4]$; the Is $11^{+}$cells $[5,6]$, the cardiac side population $\left(\mathrm{Abcg}^{+} / \mathrm{MDR}^{+}\right)[7,8]$, and cardiosphere-derived stem cells $\left(\mathrm{c}-\mathrm{kit}^{+} / \mathrm{Sca}^{-}{ }^{+} / \mathrm{Flk1}^{+}\right)$[9-11], have been isolated and characterized from hearts by different laboratories [1216]. There may be additional CSCs populations [17-19]. Although, the origin and the function of these cells remain unclear, different putative adult CSCis most likely represent different developmental and/or physiological stages of a unique CSC population in the adult mammalian heart [20].

The $\mathrm{c}-\mathrm{kit}^{+} / \mathrm{Lin}^{-}$cells represent one of the major CSC populations founded in the heart [21]. In both children and adults, these cells are present in highest number in the right atrial

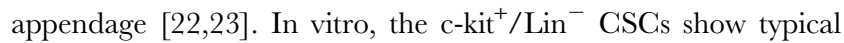
stem cell properties and pluripotency, and some in vivo studies have shown that transplantation of these cell improves cardiac function in animal models of myocardial infarct (MI). However, the results are variable. Some studies report marked improvement in function, whereas other report only marginal or non-significant effects on cardiac structural and/or function [13,24-27]. It is likely that this variability stems from the lack of understanding of the biological properties of these cells before and after transplantation and how these cells could be reproducibly identified, isolated and transplanted. In particular, issues such as the specificity of c-kit as a CSC marker, contamination from other cell source, CSC lineage and the expression of cardiac lineage markers before and after differentiation remain controversial [16,28-30].

The c-kit antigen is primarily expressed in hematopoietic stem cells, but its expression disappears in cells of hematopoietic lineage after differentiation, except for mast cells [31-33]. Therefore, it

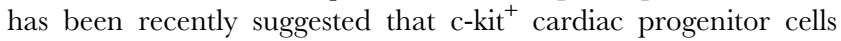
isolated from human heart tissue are actually mast cells [34]. Similarly, it is unclear whether or not the c-kit population is contaminated by other cells such as the cardiac fibroblasts, mast cells or hematopoietic lineage cells and whether the expression of c-kit remains stable after tissue processing and long-term cell culture. Data on the expression of lineage markers are even more 
conflicted. For instance, Anversa and colleagues reported that human c-kit $^{+}$cells (both cloned and uncloned CSCs), do not express all the cardiac lineage markers such as GATA4, Nkx2.5, MEF2c, $\alpha$-sarcomeric actin $(\alpha$-SA), $\alpha$-smooth muscle actin $(\alpha$ SMA), CD31, and KDR before differentiation as measured by flow cytometry; whereas $4-23 \%$ of the un-fractional cell population at $\mathrm{P} 0$ was found to be positive for these markers $[12,35,36]$. In their recent study, they reported a similar lack of expression of cardiac lineage markers, except for KDR, which was found to be expressed in $\sim 3 \%$ of ${\mathrm{c}-\mathrm{kit}^{+}}^{+}$population [36]. In contrast, Itzhaki-Alfia et al have reported that the un-fractioned adult human CSCs are positive for GATA $4^{+}(60 \%)$ and cardiac $\alpha$ $\mathrm{SA}^{+}(60 \%)$ even before c-kit purification [22]. In neonatal hearts and heart tissue from young children, however, the percentages of c-kit $^{+}$ranged from $5 \%-9 \%$ and only small percentage (1\% to $3 \%$ ) of c-kit ${ }^{+}$cells were double positive for Nkx2.5 $5^{+}$[23]. Clearly, many aspects about these cells remain to be fully understood. Therefore, the present study was designed to systematically characterize the c$\mathrm{kit}^{+} / \mathrm{Lin}^{-}$CSCis isolated from adult human heart samples. We examined CSC markers adapted to post-isolation, expansion, purification, Lin depletion (Lin-dep); their vitro differentiation properties, and potential contamination by other cell types, such as cardiac fibroblasts and mast cells. The overall goal in this work was to provide essential but practical information required for optimizing the use of human CSCs for future clinical trials in MI repair.

\section{Materials and Methods}

Tissue samples of discarded atrial appendages from patients were randomly divided into 4 groups (Figure 1). Group 1 comprised of tissue sections for immunohistochemistry (IHC) to identify c-kit ${ }^{+}$cell and cardiac $\alpha$-SA or freshly isolated cells directly used for immunocytochemistry (ICG) with human c-kit specific antibody. Group 2 cells were continuously cultured at $37^{\circ} \mathrm{C}$ up to passage $10(\mathrm{P} 10)$, but without any purification or enrichment steps using c-kit or Lineage (Lin) magnetic activated cell sorting (MACS). Group 3 cells were subjected to c-kit MACS and/or Lin-dep. In the last group, isolated cells went through single or double MACS procedures with c-kit and Lin antibodies and these cells were then used for cardiac differentiation. All isolated cells were passed every 4-5 days up to P10. The cells were collected on every other passage for ICC and flow cytometry using various antibodies anti c-kit, hematopoietic Lin markers, KDR, CD31, CD34, CD45, CD133, and cardiac lineage markers (such as Nkx2.5 and GATA4).

\section{Human atrial appendages}

A total 30 atrial appendages specimens were collected from 30 patients during the routine procedure of open heart surgery from Jewish Hospital at University of Louisville. The specimens were from right atrial appendages and the size of samples varied from 50 to $500 \mathrm{mg}$. No information was able to be collected in terms of patients' age, sex, types of cardiac diseases, and properties of noncardiac diseases, and other medical history of patients based on the approved protocol. A written consent agreement was obtained for collection of discarded atrial appendages according to a protocol approved by the Institutional Review Boards on human subject research at University of Louisville.

\section{Cell dissociation and culture}

Enzymatic digestion was used to dissociate human CSCis from atrial appendages as described previously [12]. Briefly, after removing fat, the tissues were washed $3 \times$ with cold $\mathrm{Ca}^{2+} / \mathrm{Mg}^{2+}$-free PBS

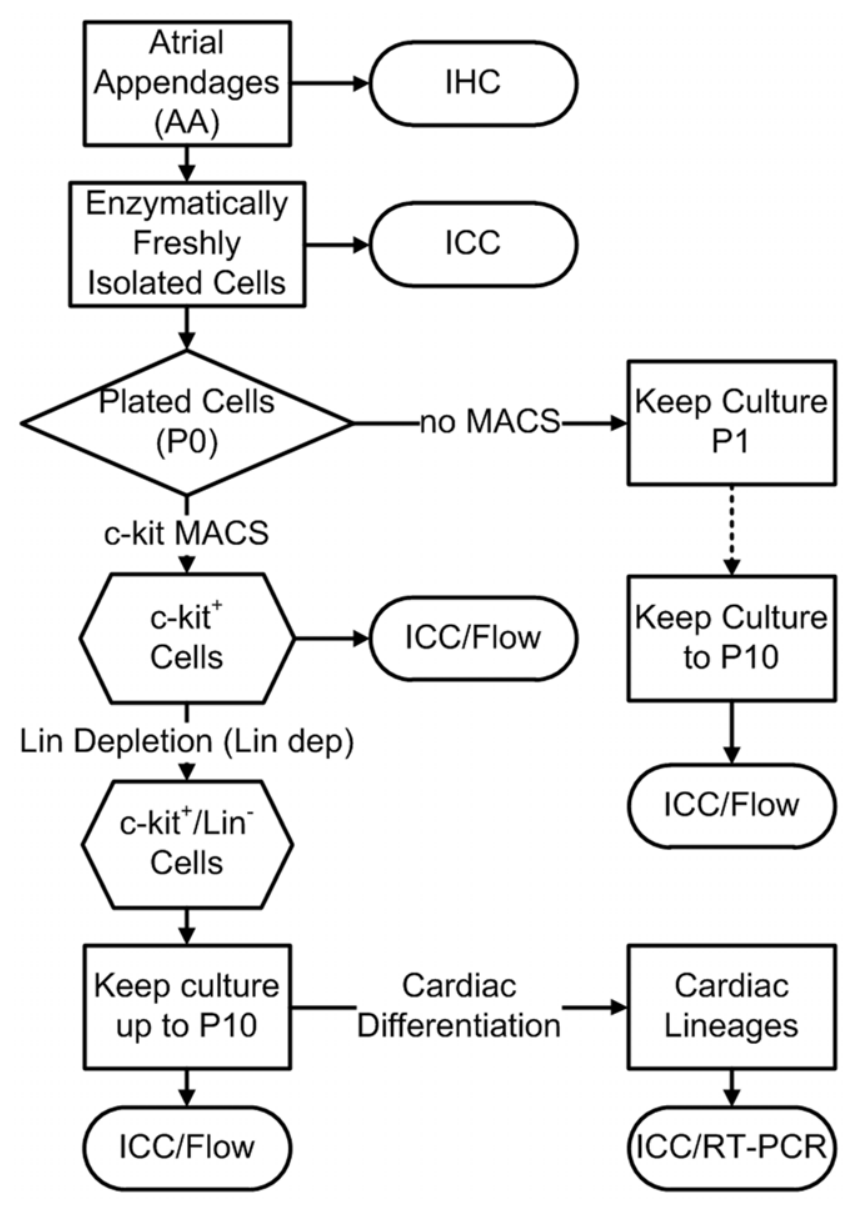

Figure 1. Experimental design. The samples of human atrial appendages $(A A)$ were randomly sorted in 4 groups and used either for immunohistochemistry (IHC) or enzymatically dissociated into single cells for Immunocytochemistry (ICC) or Flow Cytometry (Flow). The cultured cells were then underwent c-kit magnetic activated cell sorting (MACS) and/or followed by Lineage depletion (Lin-dep.) or simply kept culturing without any purification and selection. The resulting $\mathrm{c}-\mathrm{kit}^{+} /$ $\mathrm{Lin}^{-}$cardiac stem cells (CSCs) were used for cardiac differentiation and analyzed by Flow, ICC and RT-PCR.

doi:10.1371/journal.pone.0027719.g001

buffer. Thereafter, the samples were minced into small pieces $(\sim 1 \mathrm{~mm})$ and washed extensively in fresh cold PBS buffer. The chopped tissues were then transferred into $50 \mathrm{ml}$ tube and incubated with collagenase II $(30 \mathrm{U} / \mathrm{ml})$ in $37^{\circ} \mathrm{C}$ shaker for $60 \mathrm{~min}$. The loosened tissues were further mechanically dissociated by gently pipetting. The undigested tissue clumps were allowed to settle down by gravity on ice for $10 \mathrm{~min}$ followed by transferring the supernatant into another $15 \mathrm{ml}$ tube. After centrifuge at 1,400 rpm for $5 \mathrm{~min}$, the cell pellet was resuspended in fresh CSC culture medium consisting of Ham's F12 (Invitrogen, CA), 10\% FBS (Hyclone, UT), $10 \mathrm{ng} / \mathrm{ml}$ human bFGF (PeproTech, NJ), $0.2 \mathrm{mM} \mathrm{L}$-glutathione, and $0.005 \mathrm{U} / \mathrm{ml}$ human erythropoietin (both from Sigma, MO). The cells suspension was then plated in culture flask and cultured in $37^{\circ} \mathrm{C}$ incubator supplied with $95 \%$ air $/ 5 \% \mathrm{CO}_{2}$. Next day, the medium was entirely changed to remove all dead cells and cell debris. The adherent cells were continuously cultured with medium change every other day or split at 4-5 days with TrypLE Express (Invitrogen, CA). The subsequent analyses were done on the entire un-fractional population of cultured cells or after c-kit MACS and/ or Lin-dep. 


\section{Magnetic activated cells sorting (MACS)}

The c-kit ${ }^{+} / \mathrm{Lin}^{-}$CSCs were enriched using the c-kit MACS kit according to the manufacturer's instructions (Miltenyi Biotec, Germany). Briefly, total populations of adherent cells between P1 to P3 (dependent on cell density) were enzymatically dissociated into single cell suspension. The cells were collected and incubated with microbeads directly conjugated to mouse monoclonal antihuman c-kit antibody (clone AC126) at $4^{\circ} \mathrm{C}$ to $8^{\circ} \mathrm{C}$ for $20 \mathrm{~min}$. The cells were then loaded into a MACS column which was placed in the magnetic field of MACS Separator (Miltenyi Biotec, Germany). The labeled c-kit ${ }^{+}$cells were retained on the column and unlabeled cells were eluted. After column was removed from magnetic field, the magnetically retained c-kit ${ }^{+}$cells were collected as positively selected cell fraction for further expansion and analysis with ICC, flow cytometry, and/or RT-PCR.

To exclude the potential contamination of $\mathrm{Lin}^{+}$cells (such as T cells, B cells, NK cells, dendritic cells, monocytes, granulocytes, erythroid cells, and their committed precursors), a Lineage Cell Depletion Kit (Miltenyi Biotec, Germany) was used to purify c-kit ${ }^{+}$ cell populations. This kit is a biotin conjugated-monoclonal antibody cocktail consisting of CD2, CD3, CD11b, CD14, CD15, CD16, CD19, CD56, CD123 and CD235a antibodies. Similar to c-kit MACS, Lin-depletion required the cells to be incubated with the antibody cocktail at $4^{\circ} \mathrm{C}$ to $8^{\circ} \mathrm{C}$ for $15 \mathrm{~min}$ and then incubated with microbeads conjugated anti-biotin secondary antibody for another $15 \mathrm{~min}$. The magnetically labeled $\mathrm{Lin}^{+}$cells were depleted by retaining them on MACS column in magnetic field while unlabeled $\mathrm{Lin}^{-}$cells passed through the column and were collected for further expansion and/or analysis.

\section{Flow Cytometry}

Flow Cytometry was used to analyze the expression patterns of CSCs markers during cell culture. Briefly, after detaching adherent cells with TrypLE Express (Invitrogen), single cell suspension was filtered through $70 \mu \mathrm{m}$ nylon mesh and then centrifuged and washed with $2 \times 5 \mathrm{ml}$ PBS (Invitrogen). Cells were incubated on ice for 30 to $60 \mathrm{~min}$ (depending on individual antibody) with appropriate combination of fluorochrome conjugated-primary and/or secondary antibodies. The labeled cells were then washed $3 \times$ with PBS, fixed with $1 \%$ PFA for $10 \mathrm{~min}$ and resuspended in FACS buffer for flow analysis on LSRII Flow Cytometer (BD Bioscience) using FacsDave 6.0 software (BD Bioscience, CA) or FlowJo 7.5 (TreeStar, Ashland, USA). The following antibodies and dilutions used in Flow Cytometry and ICG (see below) included: (1) Unconjugated primary antibodies: rabbit IgG anti-c-kit; mouse IgG anti-GATA4 (both from Santa Cruz, CA); mouse IgG anti-Nkx2.5; mouse IgG anti-Fibroblast (both from Abcam, MA); mouse IgG anti-Tryptase (Chemicon, CA); mouse IgM anti-Cardiac $\alpha$-SA; mouse IgG anti- $\alpha-\mathrm{SMA}$; rabbit IgG anti-KDR (all from Sigma, MO). (2). Fluorochrome directly conjugated primary antibodies: mouse IgG anti-CD31APC; mouse IgG anti CD34-APC; mouse IgG anti CD45-APC; mouse IgG anti CD133-APC (all from eBioscience, CA); mouse IgG anti-Lin cocktail (CD2, CD3, CD14, CD16, CD19, CD24, CD56, CD68, CD123, CD235a-FITC (BD Bioscience, CA); (3). Secondary antibodies: donkey anti-rabbit IgG-FITC; donkey antimouse IgG-FITC (both from Invitrogen, OR); donkey anti-mouse IgM-TRITC (Jackson Immunoresearch, PA).

\section{Immunocytochemistry (ICC) and immunohistochemistry (IHC)}

The expression of CSC markers were also analyzed by immunofluorescence techniques. Briefly, freshly isolated or detached cell suspension was subjected to live-cell staining or fixation with $4 \%$ PFA before primary antibody incubation, depending on the location of antigen, i.e., an intra- or extra-cellular marker. Live-cells were incubated on ice with the primary antibody for 30-60 min and fixed-cells were incubated at room temperature for 20-45 min depending on individual antibody. In each case, PBS supplemented with $10 \%$ horse serum was used as blocking solution. The sample was incubated with an appropriate combination of fluorochrome conjugated and/or primary and secondary antibodies (see Flow Cytometry above). Cells were stained by DAPI (or Hoechst 33342 for live-cell) for identifying the nuclei. Samples were then centrifuged in Cytospin. Images were collected and analyzed using a LSM 510 META Confocal laser-scanning microscope and/or an Axiovision Fluorescence microscope (both Carl Zeiss, Germany). The percentage of positive cells of interest was estimated on the basis of total nuclei ( $\sim 300$ to $600 /$ per data set) counted from each sample slide of at least three patients.

IHC was used to determine the percentages of c-kit ${ }^{+}$in tissue sections. Briefly, the fat was removed from atrial samples, and followed by washing $3 \times$ in cold PBS buffer to remove possible blood, and tissues were then fixed in $10 \%$ formalin solution for $24 \mathrm{~h}$ followed by $70 \%$ ethanol for another day at room temperature. The fixed tissue blocks were then embedded in paraffin and sectioned at a thickness of $4 \mu \mathrm{m}$. Negative controls were included each time by omitting primary antibody with a normal procedure. Following counter-staining with DAPI, slides were mounted with fluorescence anti-fade Vectashield mounting medium under cover slip. LSM 510 META Confocal and/ or Axiovision fluorescence microscopes were used to acquire fluorescent images and percentage of c-kit ${ }^{+}$was estimated based on total nuclei $(\sim 3000)$ counted from three sections of each sample among at least three patients. The primary antibodies used were rabbit IgG anti-c-kit (Dako, CA) and mouse IgM anti-Cardiac $\alpha$-SA (Sigma, MO); the secondary antibodies included donkey anti-rabbit IgG-FITC (Invitrogen, CA) and donkey anti-mouse IgM-TRITG (Jackson ImmunoResearch, PA).

\section{RT-PCR}

Total RNA was extracted from cells using the PARIS Kit (Applied Biosystem, CA), and then treated with DNase to eliminate DNA contamination. The quality and quantity of total RNA was estimated with Nanodrop 2000c (Thermo Scientific, DE). RT-PCR was run with Qiagen Onestep RT-PCR kit according to manufacturer's instructions. For each measurement, $100 \mathrm{ng}$ of total RNA was used as a template and RT-PCR was performed using primers (from IDT, Coralville, IA) listed below at concentration of $0.5 \mu \mathrm{M}$. Cycle conditions were: $50^{\circ} \mathrm{C} / 30 \mathrm{~min}, 94^{\circ} \mathrm{C} /$ $15 \mathrm{~min}, 94^{\circ} \mathrm{C} / 30 \mathrm{~s}$ for denature, $58-60^{\circ} \mathrm{C} / 30 \mathrm{~s}$ for annealing, and $72^{\circ} \mathrm{C} / 30 \mathrm{~s}$ for extension with total cycles of 35 . PCR products were run on $2 \%$ agarose $/ 1 \times \mathrm{TBE}$ gel stained with ethidium bromide for $30 \mathrm{~min}$ (Bio-Rad, CA). The following primers were used: $c$-kit: forward-TACTGAT TCACTGCATGGCTCCCA; reverse-ACAGAGTGCCTTAAGTGCAGGTGA. GATA4: forward -CGAATGACGGCATCTGTTTGCCAT; reverse-GCAGAACAGCAATGTGCAGAGGA. ME F2c:forward-TGGCTGCATGTTTGAATCAGGTGG; reverse-AGACGACCTGTGTTACGTGC ACTT. KDR: forward-AGAGGGTTTGTTTAGGACGTGGGT; reverse-TTGAACGTCCCGCA TTCAGTCTCA. $v W F$ : forward-ACTCAGTGCATTGGTGAGGATGGA; reverse-TCGGACAC ACTCATTGATGAGGCA. Cardiac troponin I (cTnI): forward-AATCAGACGCCGCTCCTC CAAC; reverse-TCTCCCACCTCCCGGTTTTCCTTC. MLC2v: forward-AGAGGTGGGGGGA GTGTGGAAT; reverse-TTTCACGTTCACTCGCGCAAGGG. GAPDH: 
forward-AAGGTCG GAGTCAACGGATTTGGT; reverse-AGTGATGGGATGGACTGTGGTCAT.

\section{In vitro differentiation}

In vitro assays of cardiac differentiation were performed to examine three cardiac lineages, cardiomyocytes, smooth muscle, and endothelial cells, according to the modified method from

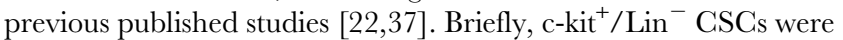
seeded in triplicates in either 6-well plates (for RT-PCR analysis) or T75 flasks (for ICG assay) and cultured for 1 to 2 days in human CSC medium. To induce cardiac differentiation, the culture medium was switched into differentiated medium consisting of DMEM (Invitrogen, CA), 10\% FBS (Hyclone, NJ), and $10 \mu \mathrm{M} 5$ azacytidine (5-AZ, Sigma, MO) for 3 days. Cells were continuously cultured up to 35 days and the medium was changed every other day. Total RNA extracted from control (Day 0) and differentiated cells (Day 3, 7, 14, 21, 28 and 35) and used to analyze gene expression patterns of cardiac lineages (c-kit, GATA4, MEF2c, KDR, vWF, cTnI, and MLC2v) by RT-PCR with specific primers purchased from IDT (see above). Protein expressions was examined only on Day 0 before differentiation and Day 35 after differentiation by ICC using cardiac lineagespecific antibodies: rabbit IgG anti c-kit (Santa Cruz, CA), mouse IgG anti-CD31-APC (eBioscience, CA), mouse IgG anti- $\alpha$-SMA, mouse IgM anti-cardiac $\alpha$-SA (both from Sigma, MO), and rabbit IgG anti-cTnI (Chemicon, CA). The secondary antibodies consisted of: donkey anti-rabbit IgG-FITC; donkey anti-mouse IgM-TRITC or FITC (c-kit) or ( $\alpha$-SMA or $\alpha$-SA) (all from Invitrogen, CA).

\section{Other materials}

Human umbilical vein endothelial cells (HUVECs, CRL-1730), human fibroblasts (CRL-110), and human Jurkat cells (TIB-152) were obtained from ATCG (Manassas, VA). Human bone marrow cells were purchased from AllCells (Emeryville, CA). Total RNA of human carotid artery was bought from Agilent Technologies (Santa Clara, CA). Cells were grown according to manufacturer's product instructions. All chemicals used were from Sigma (MO) and medium from Invitrogen (CA), unless otherwise stated.

\section{Statistical analysis}

The data are presented as mean \pm SEM (standard error of mean). Student's t test with two-tailed distributions was used to compare two groups. One-way ANOVA followed by Bonferroni test was used to compare three and more groups. $p<0.05$ was considered significantly. Cells from at least 3 patients were used for each group.

\section{Results}

\section{c-kit expression pattern in CSCs before and after c-kit MACS}

To ensure high quality and purity of the cells for future clinical trials, changes in c-kit expression were examined after isolation and/or long-term culture of human CSCs. As shown in Figure 2, ${\mathrm{c}-k i t^{+}}^{+}$cells were readily identified in section of the atrial appendages, however, only a small percentage $(\sim 0.036 \%)$ of cells (counted by nuclear staining) in the atria displayed c-kit positivity (Figure 2A.a). Estimates of the percentage of c-kit ${ }^{+}$cells in freshlydissociated single cell population from atrial appendage indicated

\section{A}
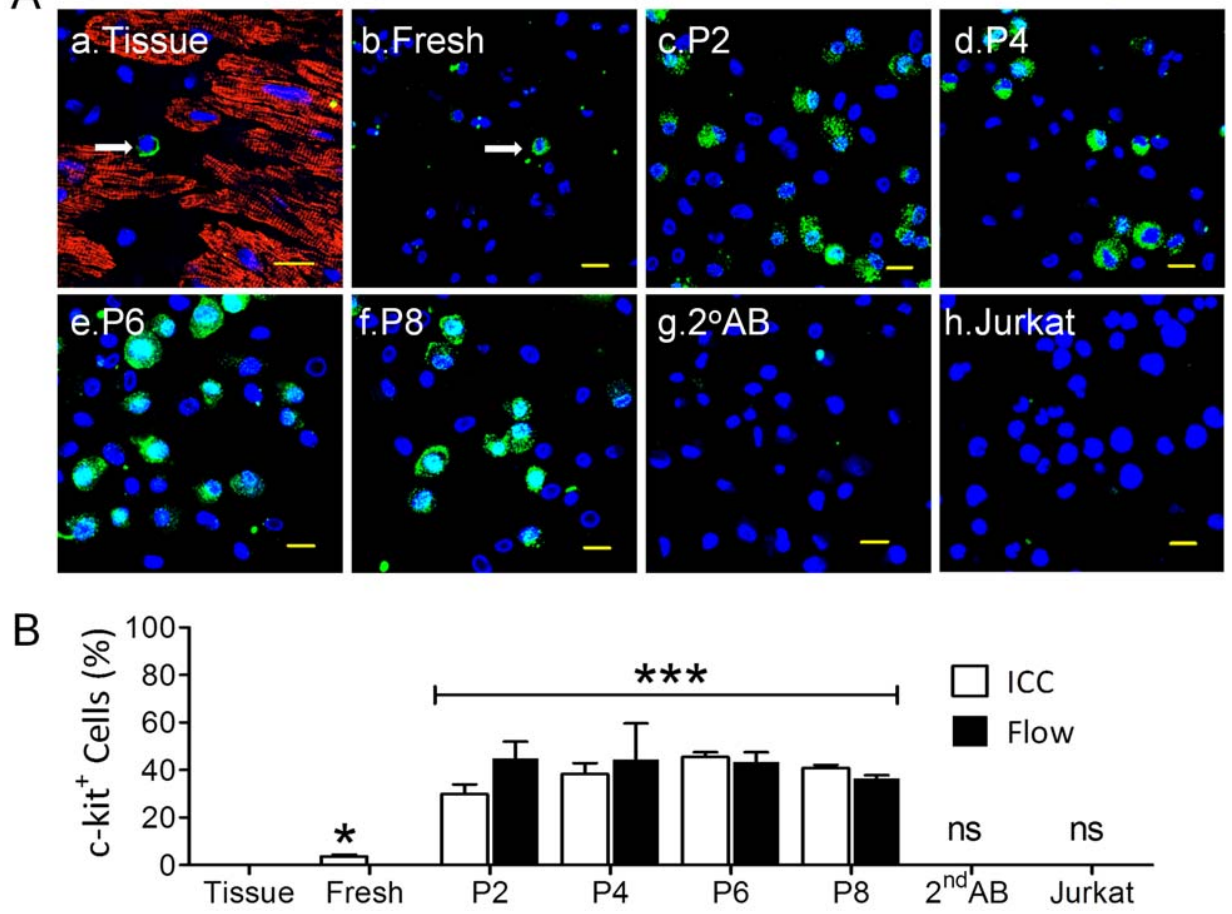

Figure 2. C-kit ${ }^{+}$cells before purification. Panel A showed the representative images on tissue section (a) of atrial appendages or freshly isolated cells before (b) and after plating (c-f) at passage 2 (P2) to P8 from the same patient. C-kit ${ }^{+}$cells were showed in green (FITC, see arrows in a and b, but all green cells in $\mathrm{c}-\mathrm{f}$ ) and nuclei were stained in blue (DAPI). The negative controls included secondary antibody (g. $\left.2^{\text {nd }} A B\right)$ alone and human Jurkat cells (h) stained with c-kit antibody. Scale bars $=20 \mu \mathrm{m}$. Panel B displayed the Mean \pm SEM data from ICC (open bar) and Flow Cytometry (filled bar). $\mathrm{n}=4-9$ patients. ${ }^{*} p<0.05,{ }^{* * *}: p<0.01$, ns: no significance, all were compared to control (Tissue).

doi:10.1371/journal.pone.0027719.g002 
that about $3.6 \pm 0.82 \%$ cells were ${\mathrm{c}-\mathrm{kit}^{+}}^{+}$as measured by ICC (Figure 2A.b and 2B). The larger number of c-kit ${ }^{+}$cells obtained in dissociated cells $(p<0.05, \mathrm{n}=4$ patients $)$ may be due to more accurate measurement of the entire cell population than those with tissue sections. However, because of a large number of dead cells, cell debris and undissociated cells in the isolate, this estimate could potentially also result in an overestimation of $\mathrm{c}^{-\mathrm{kit}^{+}}$cells. Nevertheless, both the techniques indicated that the abundance of c-kit ${ }^{+}$cells in the atrial appendage is quite low.

To evaluate the stability of c-kit expression during long-term culture, we collected cells after every other passage to examine changes in c-kit expression by ICG and flow cytometry, separately. We noted that the percentages of $\mathrm{c}^{-k i t}{ }^{+}$cells were gradually increased from $3.6 \pm 0.82 \%$ in freshly isolated cells up to $\sim 40 \%$ between $\mathrm{P} 2$ to $\mathrm{P} 8$ before c-kit magnetic selection and purification (Figure 2). The average percentages of c-kit ${ }^{+}$cells from P2 to P8 was significantly higher than tissues section and freshly isolated cells $(p<0.01, \mathrm{n}=4$ to 9 patients, Figure 2B). Because mature lymphocytes do not express c-kit [38], we used a cloned human Jurkat cell line (T lymphocyte) and $2^{\text {nd }}$ antibody as negative controls to exclude potential false positive. Our data showed that both control groups produced no c-kit ${ }^{+}$staining (Figure 2A.g and h).

To purify and enrich c-kit ${ }^{+}$CSCs, cultured cells were enzymatically detached at passage 1 to 2 and c-kit MACS was performed through column with un-fractional single cell population after incubation with human c-kit antibody-conjugated magnetic beads (see Materials and Methods). As shown in Figure 3 , the percentage of $\mathrm{c}^{-\mathrm{kit}^{+}}$cells in the population increased dramatically up to $\sim 80 \%$, as analyzed by flow cytometry (Figure 3A, upper row) and ICG (Figure 3A, lower row). On average, $79.1 \pm 3.2 \%$ and $87.2 \% \pm 2.1 \%$ cells were identified to be c-kit $^{+}$by ICC and flow cytometry, respectively, between passage 2 and $10(\mathrm{n}=3)$. There was no statistically significant difference between these passages, indicating that the c-kit expression was quite stable during long-term culture for up to 10 passages for a total of 40 to 50 days. In addition, karyotyping analysis of sorted CSCs was normal both at lower (P3) and high (P10) passages with $46 \mathrm{XY}$ or YY based on total 60 cells from three patient samples (data not shown). Moreover, $\mathrm{c}-\mathrm{kit}^{+}$cells demonstrated the typical stem cell property of clonogenesis (data no shown). Collectively, these data indicate that the percentage of $\mathrm{c}^{-\mathrm{kit}^{+}}$cells in intact heart section of atrial appendages is much lower than in freshly isolated cells and continuous culture of un-fractionated cells without any purification for c-kit. The population could be further enriched by c-kit MACS and that once isolated these cells stably express the ckit antigen.

\section{Expression of hematopoietic markers in CSCs}

Having established the abundance and the stability of c-kit ${ }^{+}$cells in culture, we next examined whether the ${\mathrm{c}-\mathrm{kit}^{+}}^{+}$population isolated from the atrial appendage was contaminated by hematopoietic stem cells (which also express c-kit) or cells of hematopoietic lineage
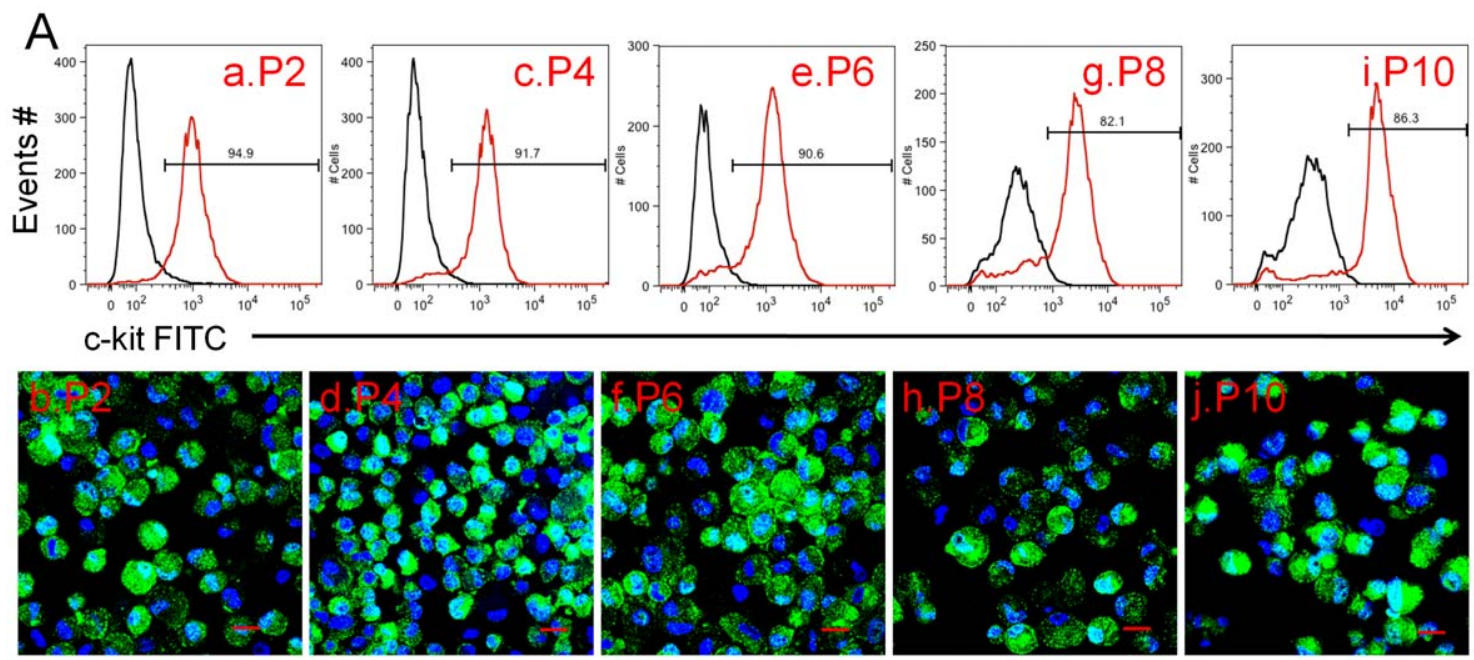

$\mathrm{B}$

ICC $\square$ Flow

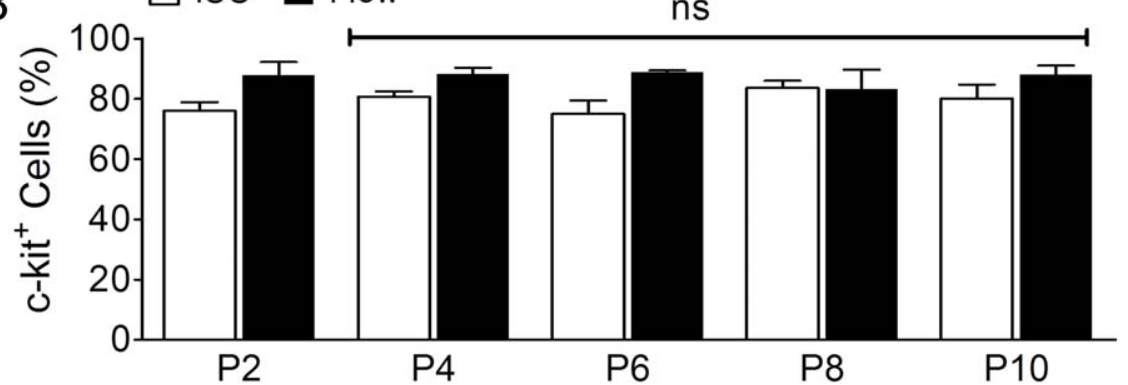

Figure 3. C-kit ${ }^{+}$cells after purification. Panel A showed the representative data of Flow Cytometry (upper row), where c-kit-FITC was shown on $x$-axis, cell Events\# was on $y$-axis, and the percentages of $c$-kit ${ }^{+}$cells was in red histograms. The representative images of ICC from the same patient was displayed in middle row, where c-kit ${ }^{+}$cells were showed in green (FITC) and nuclei were stained in blue (DAPI) at P2-P10 after c-kit MACS but without Lin-dep. Scale bar $=20 \mu \mathrm{m}$. Panel B displayed the Mean \pm SEM data from ICC (open bar) and Flow Cytometry (filled bar). The percentages of c$\mathrm{kit}^{+}$cells by ICC and Flow showed no statistical significant difference (ns) compared to $P 2 . n=3$ patients.

doi:10.1371/journal.pone.0027719.g003 
(which do not). For this, we examined several markers of hematopoietic cells. In addition to c-kit (CD117) hematopoietic stem cells express other hematopoietic markers, including CD31, CD34, CD38, CD45, CD59, CD90, CD105, CD106, CD133, CD164, CD184, CD201, and CD202 [39]. However, the mature hematopoietic cells (T/B lymphocytes, monocytes, granulocytes, and NK cells) express Lin markers, such as CD2, CD3, CD4, CD5, CD8, CD11b, CD13, CD14, CD16, CD18, CD19, CD20, CD24, CD33, CD56, CD61, CD66, CD71, CD 235, and Ter119 [39]. Therefore, to identify contaminating cells we measured these markers in the c-kit ${ }^{+}$cell population.

We found that without any selection procedures, freshly isolated cells from the atrial appendage contained $\sim 10 \%$ of $\mathrm{Lin}^{+}$cells (Figure 4A.a, e, I and 4B) as identified by ICC using a mixed Lin antibody cocktail consisting of CD2, CD3, CD14, CD16, CD19, CD20 and CD56. To exclude the possible contamination from hematopoietic stem cells the following three sets of experiments $(\mathrm{n}=3$ patients for each set) were performed in various combination of c-kit MACS and Lin-dep showed in Figure 4: (a) Freshly isolated cells were subjected to c-kit MACS followed by Lin-dep between P1 to P2 (top row). After a two-step MACS procedure, barely any $\operatorname{Lin}^{+}$cells were seen (Figure 4A.c, d and 4B); (b) Freshly isolated cells were subjected to c-kit MACS, but no Lin-dep, in which $\mathrm{Lin}^{+}$cells disappeared afterwards (middle row, Figure 4A.g., f, 4B); (c) Freshly isolated cells were continuously cultured without c-kit MACS and Lin-dep, where Lin+ cells also disappeared (bottom row, Figure 4A.k, 1 and 4B). In all three groups, the average percentage of $\mathrm{Lin}^{+}$cells was $12.3 \pm 0.9 \%$ in freshly isolated cells $(\mathrm{n}=3$ patients), however, these cells were undetectable after one or two passages whether or not Lin-dep step was applied. However, the percentages of c-kit ${ }^{+}$cells remained high with or without Lin-dep (data not shown), similar to the levels shown in Figure 2.

To confirm these results, the cells were treated with c-kit (FITG) v.s. Lin (-APG) specific antibodies, and antibody binding was detected by flow cytometry. As showed in Figure 4C and 4D, $\mathrm{Lin}^{+}$cells were not detectable after c-kit MACS whether or not Lin-dep was used. Although the percentages of $\mathrm{c}-\mathrm{kit}^{+} / \mathrm{Lin}^{-}$cells were slightly reduced after c-kit MACS, from 79.5 $\pm 3.1 \%$ (before Lin) to $65.6 \pm 10.8 \%$, the difference did not reach statistical significance (Figure 4D, ns, $\mathrm{n}=3$ patients). In control experiments with human bone marrow cells using two different measurements (ICG vs Flow), we obtained comparable percentages of $\mathrm{Lin}^{+}$cells $-64.7 \pm 2.0 \%$ by ICG (Figure 4B) vs $50.5 \pm 4.4 \%$ by flow cytometry (Figure 4D). A small population $13.4 \pm 2.5 \%$ of cells was c-kit ${ }^{+}$(Figure $4 \mathrm{D} ; \mathrm{n}=3$ in each group).

To assess contamination by hematopoietic stem cells, the expression of hematopoietic stem cells markers (CD34, CD45 and CD 133) was analyzed in the $\mathrm{c}^{-\mathrm{kit}^{+}}$cell population. Although the percentages of ${\mathrm{c}-\mathrm{kit}^{+}}^{+}$cells remained high at $74.3 \pm 4.3 \%$ and $68.5 \pm 13.3 \%$ (CD34), at $74.8 \pm 4.8 \%$ and $71.4 \pm 13.5 \%$ (CD45), and at $85.6 \pm 5.6 \%$ and $61.6 \pm 14.2 \%(\mathrm{CD} 133)$ before and after Lin-dep ( $\mathrm{n}=3$ patients in each group), respectively, there was no detectable signals of $\mathrm{CD} 34^{+}, \mathrm{CD} 45^{+}$and $\mathrm{CD} 133^{+}$cells in $\mathrm{c}-\mathrm{kit}^{+}$ cells whether or not Lin-dep was used (Figure 5). Using human bone marrow cells as positive control, we found that $20.3 \pm 6.6 \%$ (ranging from $11 \pm 0.85 \%$ in $\mathrm{CD} 45,23.7 \pm 1.6 \%$ in $\mathrm{CD} 133$, to $26.1 \pm 10.4 \%$ in CD34 group, respectively) were c-kit ${ }^{+}$, whereas the abundance of CD $34^{+}$cells was $4.5 \pm 1.8 \%, \mathrm{CD}^{+} 5^{+}$cells was $45.9 \pm 10.5 \%$, and $\mathrm{CD} 133^{+}$cells was $0.5 \pm 0.2 \%$ (Figure $5 \mathrm{~B}, 5 \mathrm{C}$, and $5 \mathrm{D}, \mathrm{n}=3$ patients). Collectively, these data indicate that single-step purification by c-kit MACS is sufficient to produce a highly enriched c-kit cell population and that the inclusion of an additional step of Lin-dep does not lead to an increase in the percentage of $\mathrm{c}^{-\mathrm{kit}^{+}}$cells in long-term culture up to 10 passages. The resultant c-kit ${ }^{+}$cell population did not express Lin markers or typical hematopoietic stem cell markers (like CD34, CD45, or CD133), indicating that cell population after c-kit MACS is not contaminated by hematopoietic stem cells or mature leukocytes of hematopoietic origin.

\section{Contamination by fibroblasts and mast cells}

Previous studies have shown that cardiac fibroblasts represent a heterogeneous population in the heart with regard to their phenotype, specific functions, and cellular origins [40]. To exclude the possibility that isolated cells from atrial appendages are fibroblasts or contaminated with fibroblasts, we measured the abundance of fibroblasts in the $\mathrm{c}^{-\mathrm{kit}^{+}}$cell population using a fibroblast-specific antibody raised against "Fibroblast Surface Protein" (FSP) [41-44]. We found that a small proportion of un-fractional cells isolated from atrial appendages were fibroblast positive cells $(22.7 \pm 0.9 \%, \mathrm{n}=3$ patients); however, these fibroblasts were entirely removed by c-kit MACS procedure (Figure 6). As a positive control, we examined human fibroblasts, which showed that $93.3 \pm 1.2 \%$ of the population was $\mathrm{FSP}^{+}$, whereas a negative control using $2^{\text {nd }}$ antibody failed to generate a positive signal for fibroblasts (Figure 6).

Although the c-kit antigen has been widely used to identify stems cells in the heart [13], this antigen is also expressed by cardiac mast cells [45]. Thus, in principle, it is possible that some of the stem cell recognized in the heart may be mast cells. To exclude this possibility, we used a well-documented mast cellspecific antibody, Tryptase $[23,33,34,46]$ to examine mast cell contamination in the sorted c-kit ${ }^{+}$cell population. However, as shown in Figure 7, we did not observe any tryptase ${ }^{+}$mast cells in ckit $^{+}$cells isolated from three different patients $(\mathrm{n}=3)$. In contrast, a small percentage $(0.95 \pm 0.3 \%, \mathrm{n}=3$ ) of human bone marrow cells displayed positive staining by the mast cell antibody (Figure 7). These data clearly showed that the c-kit ${ }^{+}$cell population isolated from atrial appendages was not contaminated by fibroblast and ckit reactivity of these cells could not be attributed to the presence of cardiac mast cells.

\section{Cardiac lineage differentiation}

The CSCs are believed to be the pre-committed cardiacresident stem or progenitor cells and therefore, they should carry typical stem cell and/or cardiac markers (like c-kit and GATA4 etc). These cells also have the capability to differentiate into three cardiac lineages both in vitro and in vivo under certain condition. Therefore, we examined changes in markers of cardiomyocytes (MEF2C, GATA4, Nkx2.5, $\alpha$-SA, cTnI, and MLC2v), smooth muscle cells ( $\alpha$-SMA), and endothelial markers (CD31, KDR, and vWF) before and after differentiation of the c-kit ${ }^{+}$cell population. Before induced differentiation, the unsorted cell population from a majority of patients contained $17 \pm 2.5 \% \mathrm{CD} 31^{+}$cells as measured by ICG (Figure 8A.a, and $8 \mathrm{~B}, \mathrm{n}=5$ patients) and $21.7 \pm 2.6 \%$ $\mathrm{CD} 31^{+}$cells as measured by flow cytometry ( $\mathrm{n}=3$ patients, data not shown). These "contaminating" CD $31^{+}$cells could be removed by c-kit MACS (Figure 8A.b). However in two cases (2 out of 7; Figure 8A.c and d, $\mathrm{n}=2$ ), unsorted cells demonstrated similar percentages $(15 \%$ and $21 \%)$ of $\mathrm{CD} 31^{+}$cells before c-kit MACS, but interestingly, but $18-20 \% \mathrm{CD}^{+} 1^{+}$cells were still present after c-kit MACS (data not shown), indicating a unique subtype of c-kit ${ }^{+} / \mathrm{CD} 31^{+}$among c-kit ${ }^{+}$cell population. Moreover, in a majority of patients (5 out of 7 ) $11.7 \pm 1.2 \%$ of the cells identified by ICC and $19.1 \pm 1.2 \%$ of the cells identified by flow cytometry ( $\mathrm{n}=3$ patients, data not shown) were $\mathrm{KDR}^{+}$before c-kit MACS (Figure 8C.f. and 8D, $\mathrm{n}=5$ patients). Like the $\mathrm{CD} 31^{+}$cells, 
A

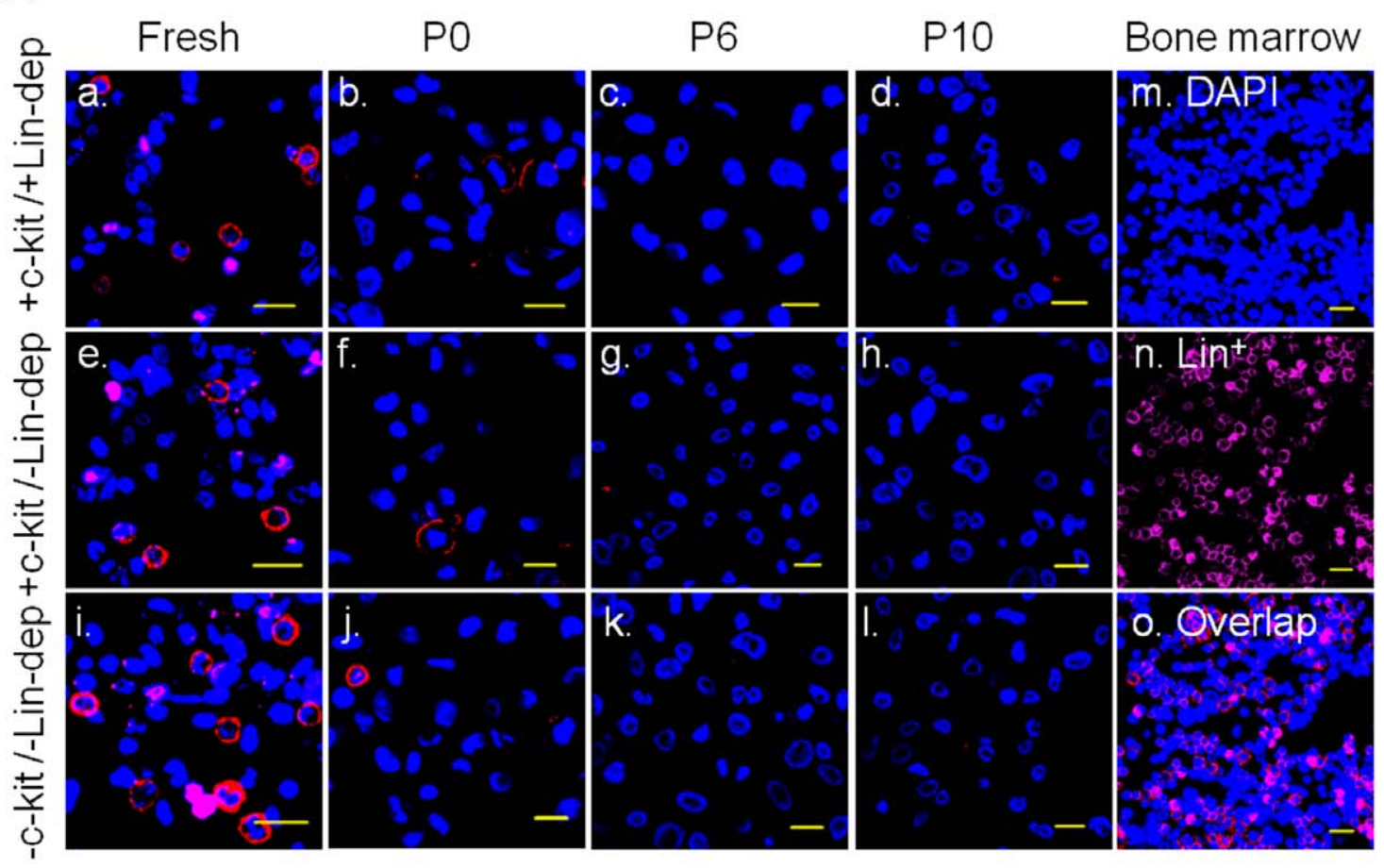

B

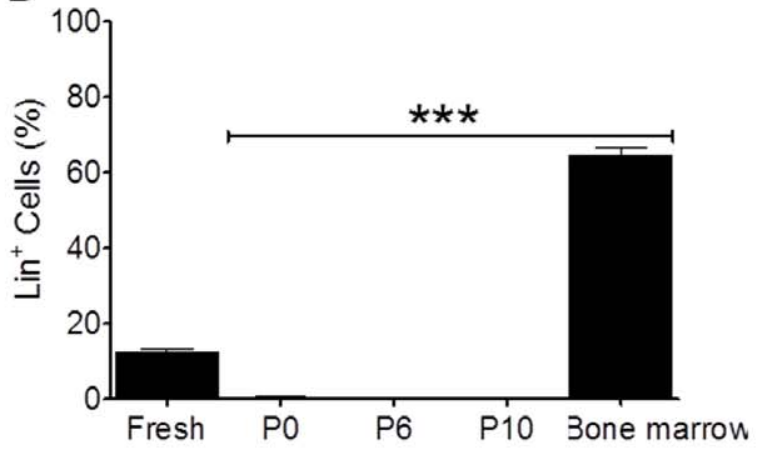

D

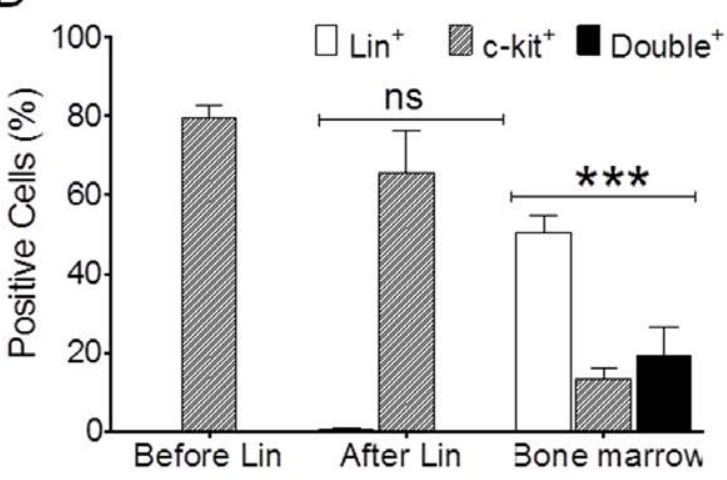

C

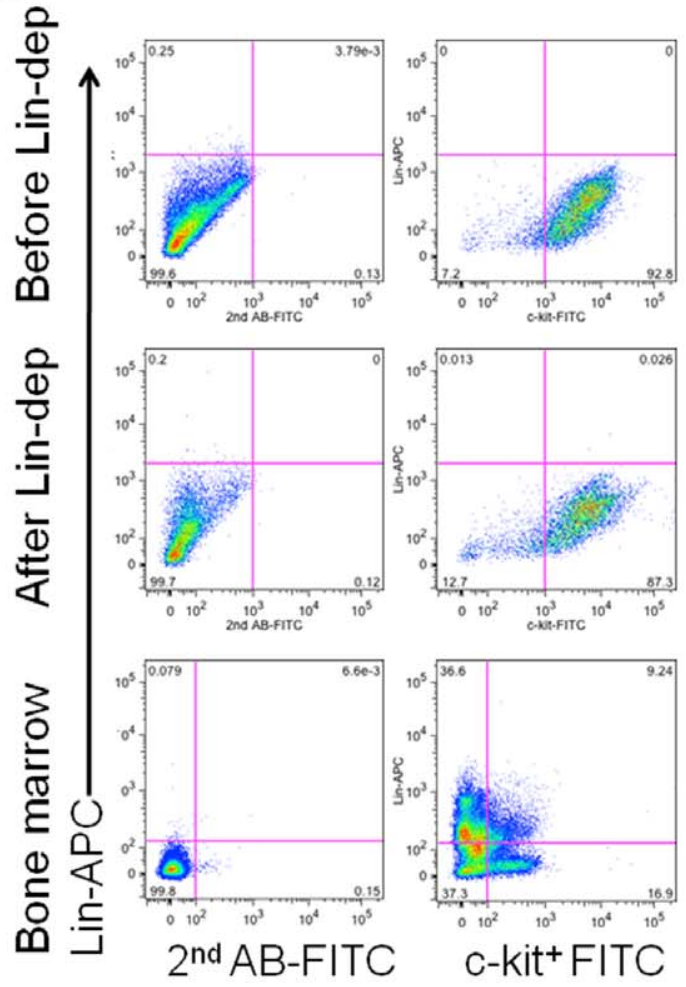

Figure 4. Lineage positive $\left(\operatorname{Lin}^{+}\right)$cells. Panel A showed the representative Confocal images of Lin $^{+}$antibody staining (red-APC) on freshly isolated cells as well as plated cells at P0, P6, and P10 with (+) and/or without $(-)$ c-kit MACS and/or Lin-dep (Panel A, top row-with c-kit and Lin-dep; middle row with c-kit, but without Lin-dep; and bottom row without c-kit and Lin-dep). Cell nuclei were stained in blue-DAPI, and Scale bars $=20 \mu \mathrm{m}$. MACS were able to be performed at P1 to P2. Human bone marrow ( $m$ to o) was used as a positive control for Lin markers (red-APC). Panel B showed the Mean \pm SEM data from ICC. ***: $p<0.001$ (P0, P6, P10 and human bone marrow) compared with control group (Fresh isolated cells). Panel C displayed the representative data of Flow Cytometry with double staining of c-kit-FITC ( $x$-axis) and Lin-APC (y-axis) in CSCs before (upper) and after (middle) Lindep. Human bone marrow was used as positive control (lower). Panel D showed the Mean \pm SEM) data of Flow Cytometry from three patients. ***: $p<0.001$ and ns: no significance; both were compared with control level (Before Lin-dep). doi:10.1371/journal.pone.0027719.g004 
A

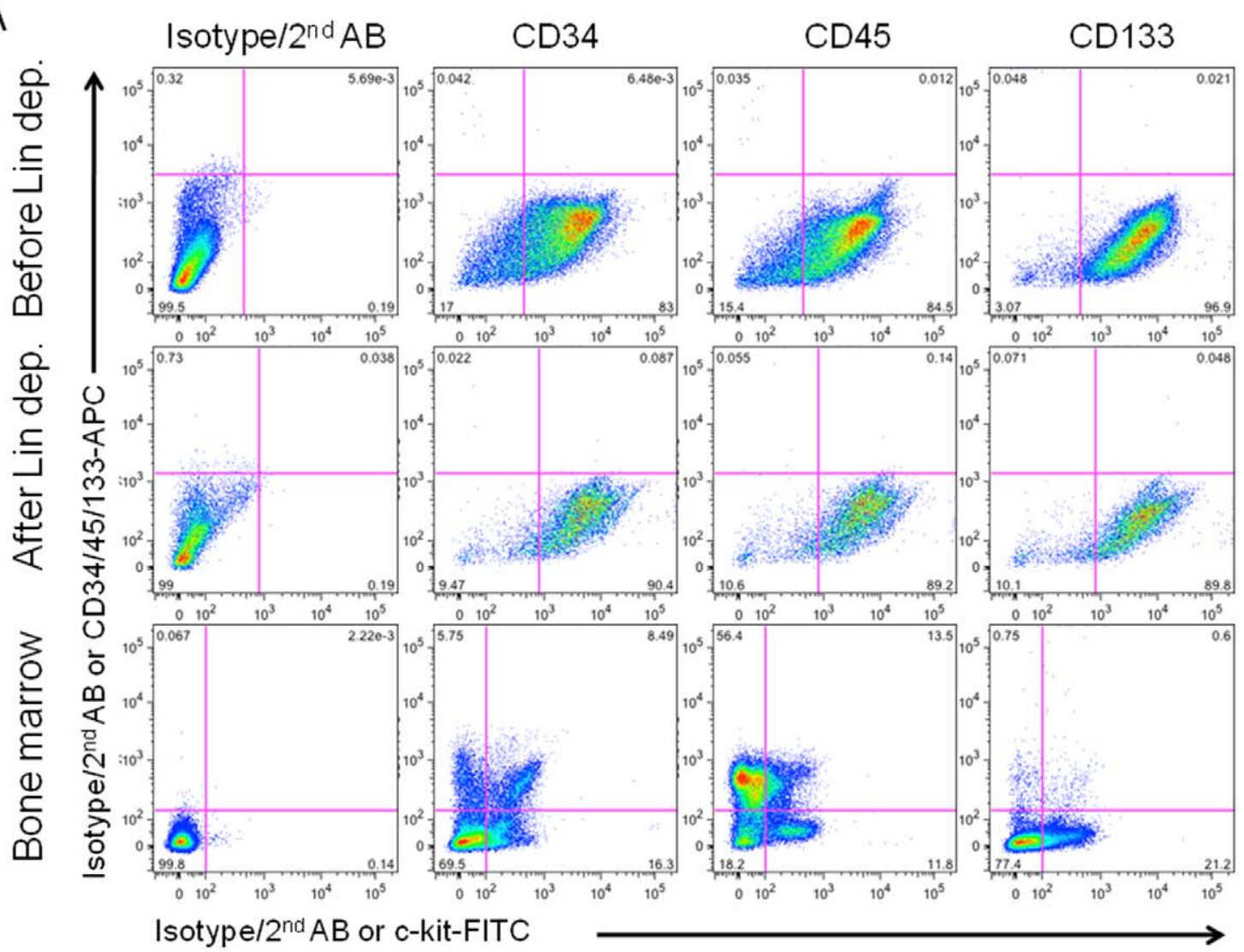

B

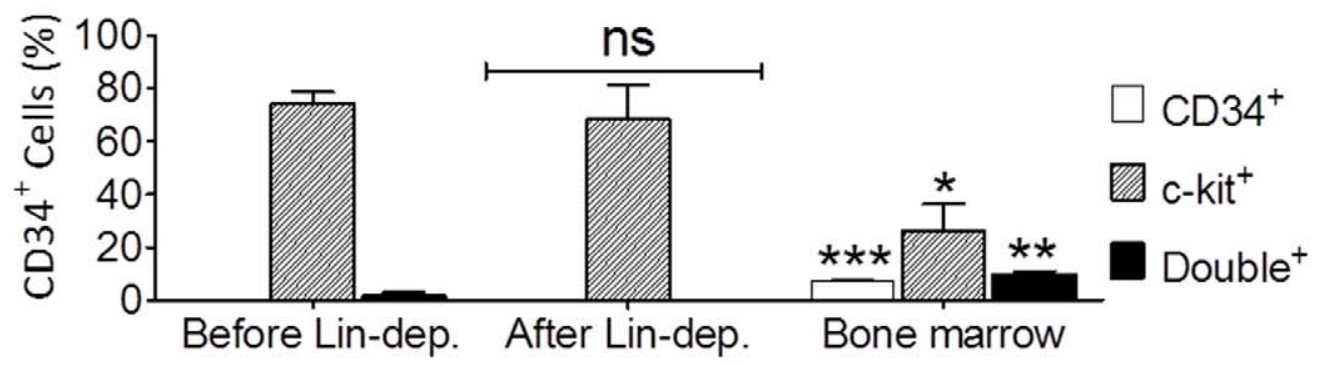

C

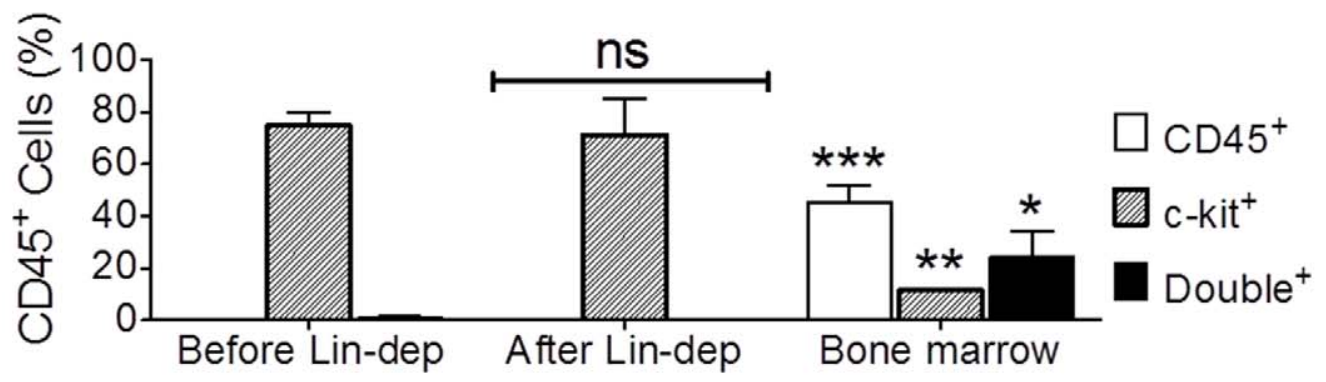

D

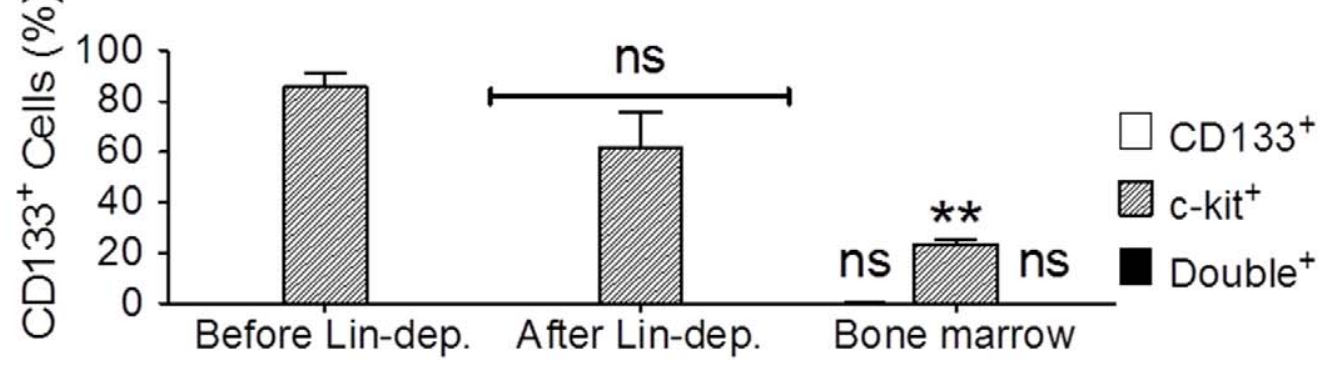


Figure 5. Expression of hematopoietic markers. Panel A displayed the representative data of Flow Cytometry with double staining of c-kit-FITC (x-axis) vs CD34, CD45, or CD133 (all-APC in y-axis) in c-kit ${ }^{+}$cell population before (top row) and after (middle row) Lin-dep. Human bone marrow (bottom row) was used as positive control. Panel B, C, and D represent the Mean \pm SEM data of CD34, CD45, and CD133, respectively. Human bone marrow cells were used as positive control in each group. ${ }^{*}: p<0.05,{ }^{* *}: p<: 0.01,{ }^{* * *}: p<0.001$; ns: no significance. Each data was compared with the corresponding control levels (Before Lin-dep.).

doi:10.1371/journal.pone.0027719.g005

the $\mathrm{KDR}^{+}$cells could also be removed by c-kit MACS (Figure 8C.f and $\mathrm{g})$. However, in two patients, the $\mathrm{KDR}^{+}$cells in c-kit ${ }^{+}$ population were not able to be removed before $(13 \%$ and $17 \%$, also see Figure 8 C.h) or after (18\% and 16\%, also see Figure 8 C.i) c-kit MACS, indicating the presence of a c-kit ${ }^{+} / \mathrm{KDR}^{+}$subpopulation of cells (Figure 8C. h and i). Dual staining of c-kit ${ }^{+}$cells with CD31 and KDR antibodies indicated that they co-express these antigens in various combination, suggesting existence of c-

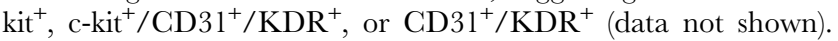
When HUVECs were used as a positive control, we observed high percentages of $\mathrm{CD}^{+} 1^{+}(96.7 \pm 0.7 \%$ by ICG and $97.3 \pm 0.7 \%$ by flow, Figure $8 \mathrm{~B})$ as well as $\mathrm{KDR}^{+}$cells $(69.3 \pm 4.1 \%$ by ICG and $68.3 \pm 2.0 \%$ by flow; Figure $8 \mathrm{D}$ ) in the cell population. From these data we conclude that the ${\mathrm{c}-\mathrm{kit}^{+}}^{+}$cells contain a distinct population

\section{A}
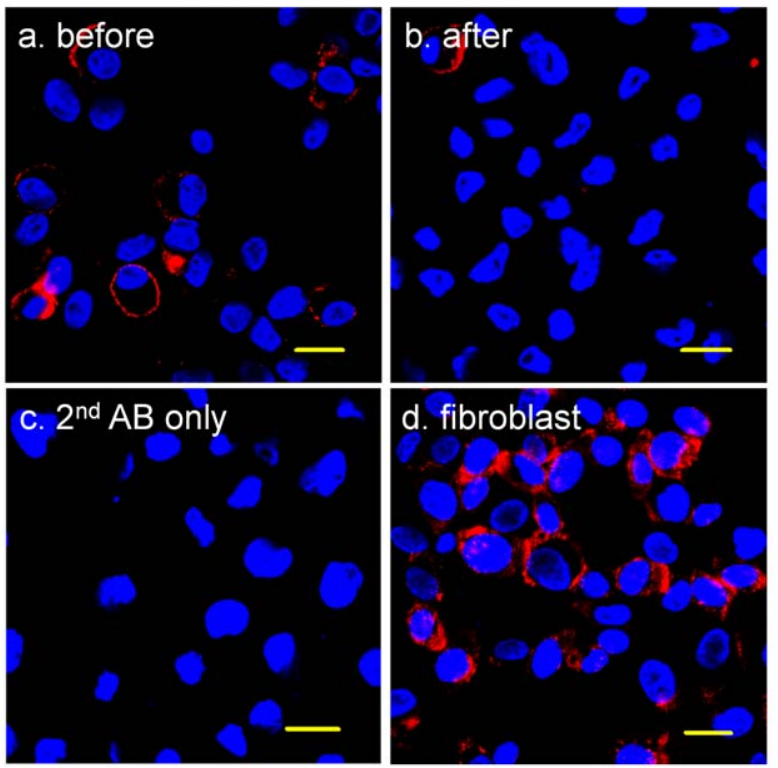

B

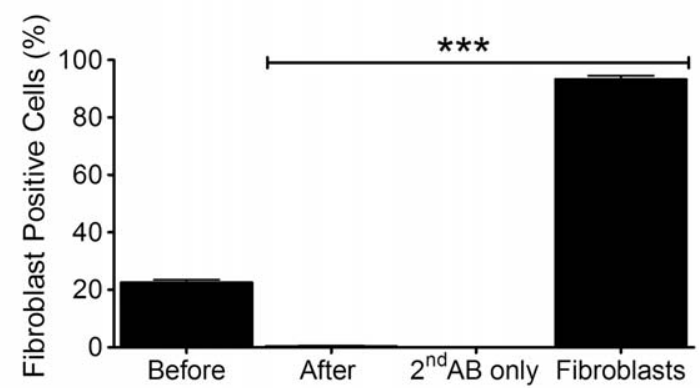

Figure 6. Fibroblast specific antibody staining. Panel $A$ showed the representative images of fibroblast antibody (Fibroblast Surface Protein in red-APC) staining on human CSCs before (a) and after (b) c-kit MACS. The $2^{\text {nd }}$ antibody-APC ( $c, 2^{\text {nd }} A B$ only) and human fibroblast cell line (d) were used as positive and negative controls, respectively. Cell nuclei were stained in blue (DAPI). Scale bars $=20 \mu \mathrm{m}$. Panel B showed the Mean \pm SEM data of ICC staining from three patients $(n=3$ patients). ${ }^{* * *}: p<0.001$ compared with control (Before c-kit MACS). doi:10.1371/journal.pone.0027719.g006 of $\mathrm{CD} 31^{+} / \mathrm{KDR}^{+}$cells. Because these cells were observed in only a sub-set of patients, their presence in the heart may be related to the medical history of these patients, their disease condition or other clinical factors. However, for now, their potential role remains unclear.

Although the sorted c-kit ${ }^{+}$cells expressed several early cardiacspecific transcription factors (GATA4 \& Nkx2.5, Figure 9), the expression of late cardiac lineage markers $(\alpha-\mathrm{SA}, \mathrm{cTnI}, \mathrm{MLC} 2 \mathrm{v}$, VWF, CD31, \& $\alpha$-SMA) was low or undetectable both at gene and protein levels (Figure 10). Specifically, RT-PCR data clearly showed specific bands for GATA4 \& MEF2c in c-kit ${ }^{+}$cells, but no expression of late cardiac genes (cTnI and MLC2v) was observed (Figure 10). By ICC analysis, we confirmed that $>80 \%$ of sorted c$\mathrm{kit}^{+}$cell population expressed c-kit ${ }^{+}$antigen (also see Figure 3), among which there were about $47 \pm 3.5 \%$ GATA $^{+}, 24.3 \pm 1.5 \%$ $\mathrm{Nkx} 2.5^{+}, 9.3 \% \pm 2.2 \% \alpha-\mathrm{SA}^{+}, 4.1 \pm 0.4 \% \alpha-\mathrm{SMA}^{+}$cells. No cTnI ${ }^{+}$ cells were detected (Figure 9 and Figure 10, $\mathrm{n}=3$ patients for each group). We found that the GATA $4^{+}$or $\mathrm{Nkx} 2.5^{+}$cells were always c-kit positive, but c-kit ${ }^{+}$cells were not always $\mathrm{GATA}^{+} / \mathrm{Nkx} 2.5^{+}$ positive (Figure 9).

Measurements of $\alpha$-SMA by ICC demonstrated low levels of expression $\left(4.1 \pm 0.4 \%, \mathrm{n}=3\right.$ patients) in c-kit ${ }^{+}$populations before differentiation (Figure 10). The low abundance of this antigen may

\section{A}
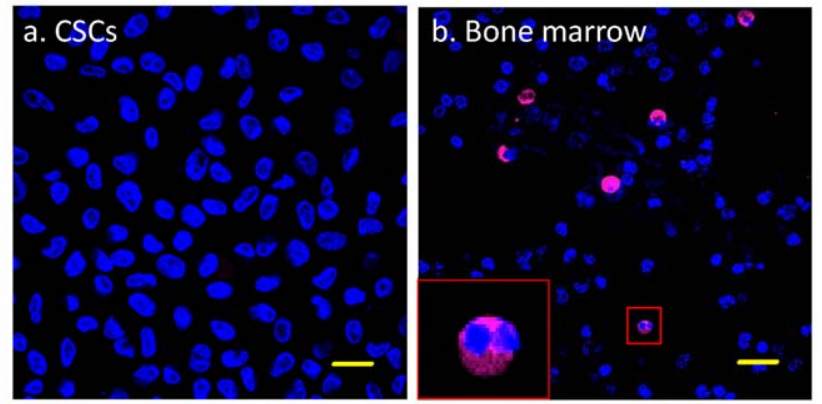

B

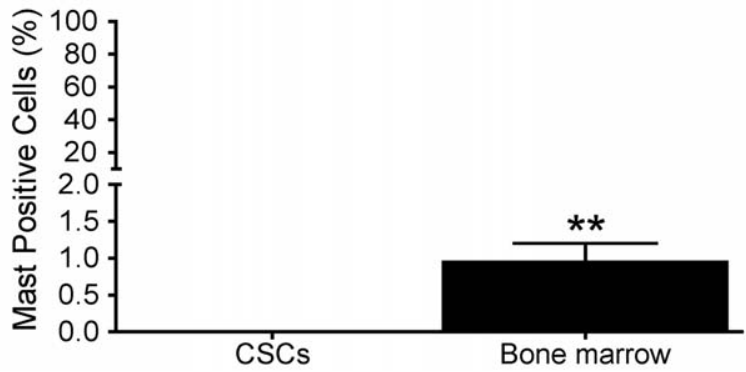

Figure 7. Mast cell specific antibody staining. Panel A demonstrated the representative Confocal images of mast cell specific antibody staining (Tryptase, red-APC) on c-kit ${ }^{+}$CSCs (a). Human bone marrow (b) was used as positive control; the inset in b was an enlarged image of a mast positive cell. Nuclei were stained in blue (DAPI). Scale bars $=20 \mu \mathrm{m}$. Panel B showed the Mean \pm SEM of ICC data from three patients ( $\mathrm{n}=3$ patients). ${ }^{* *}: p<0.001$ compared to human CSCs. doi:10.1371/journal.pone.0027719.g007 
A

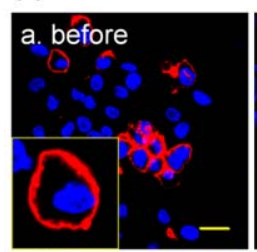

c. before

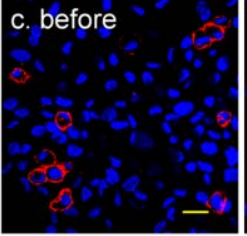

d. after

B

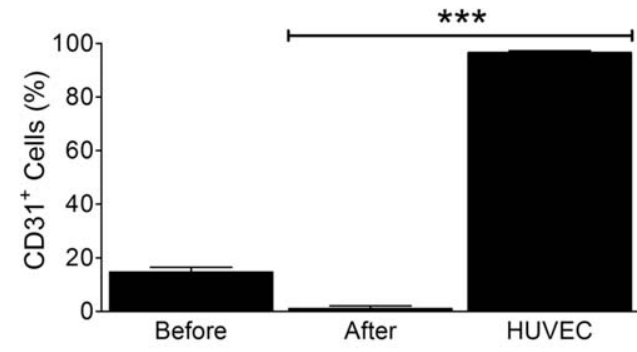

C
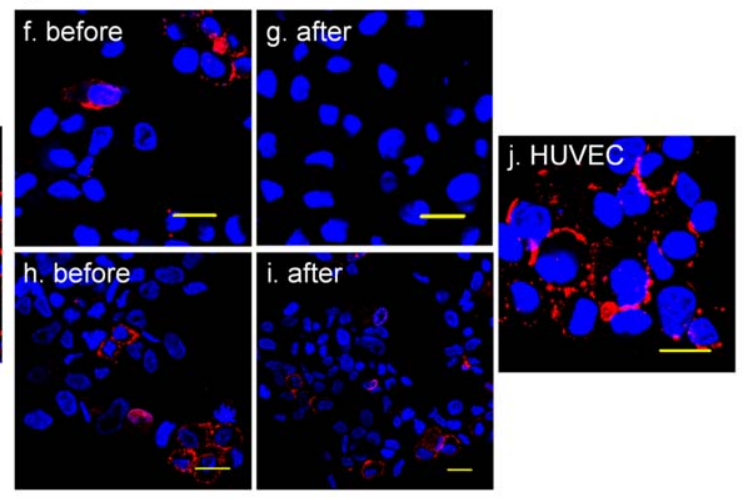

D

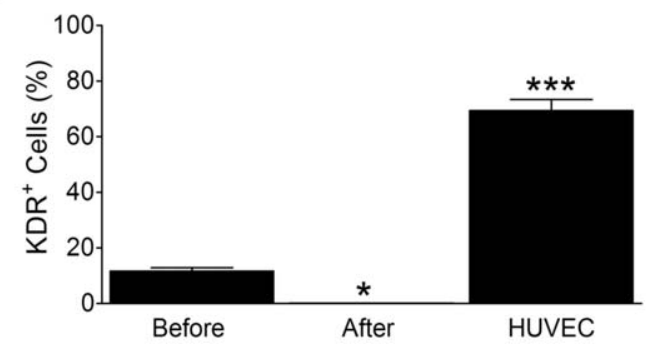

Figure 8. Endothelial specific antibody staining. Panel A showed the representative images of CD31 antibody staining before (a and $c$ ) and after (b and d) c-kit MACS in two different subtypes of cell populations in patients. Majority patients (Group 1) did not displayed CD31 ${ }^{+}$cells after $c-k i t$ MACS ( $a$ and $b$ ), but few patients (Group 2, $n=2$ ) still demonstrated the reproduced CD31 $1^{+}$cells after c-kit MACS (c and d). In all images, CD31 ${ }^{+}$cells were labeled in red (APC) and nuclei were stained in blue (DAPI). HUVECs (e) were used as positive control. Scale bars $=20 \mu \mathrm{m}$. Panel B only showed the Mean \pm SEM of CD31 antibody staining in Group $1\left(n=5\right.$ patients). ${ }^{* * *}: p<0.001$ compared to control (Before c-kit MACS). Panel C confirmed the above results with different endothelial specific antibody (KDR). The percentages of KDR ${ }^{+}$cells before $(f, h)$ and after ( $g$, i) c-kit MACS in two groups ( $f$ and $\mathrm{g}$ in Group 1, $\mathrm{h}$ and $\mathrm{i}$ in Group 2) were similar to those in CD31 experiments mentioned above. In the images, KDR ${ }^{+}$cells were labeled in red (APC) and nuclei were stained in blue (DAPI). HUVECs (j) were used as positive control. Scale bars $=20 \mu \mathrm{m}$. Panel D only showed the Mean \pm SEM of KDR antibody staining of Group 1. $\mathrm{n}=3$ patients. ${ }^{*}: p<,{ }^{* * *}: p<0.001$ compared to control (Before c-kit MACS).

doi:10.1371/journal.pone.0027719.g008

reflect the double positive cells $\left(\mathrm{c}-\mathrm{kit}^{+} / \alpha-\mathrm{SMA}^{+}\right)$found in tissue section of the human heart [12]. No positive staining was found when the secondary antibody alone was used as a negative control (data not shown). The presence of $\alpha-\mathrm{SMA}^{+}$cells in $\mathrm{c}-\mathrm{kit}^{+} / \mathrm{Lin}^{-}$ C.SCs suggests that some of these cells are pre-committed to a cardiac lineage in situ before ex vivo differentiation.

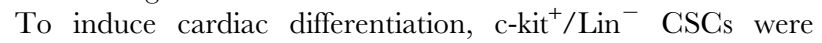
treated with $10 \mu \mathrm{M}$ 5-azacytidine (5-AZ) for three days [22,37]. Total RNA was extracted for RT-PCR analysis before (Day 0 ) and after differentiation on Day 3, 7, 14, 21, 28 and 35. As shown in Figure 10A, c-kit (stem cell marker), GATA4, MEF2C (both are cardiac markers) and KDR (endothelial marker) mRNA were expressed both before and after differentiation. However, after differentiation, the expression of $\mathrm{vWF}$ (endothelia marker), cTnI and MLC2v (late cardiac markers) was gradually increased. The mRNAs appeared on Day 7 and were continuously increased thereafter. No significant differences were observed in the levels of these mRNA between Day 28 and Day 35. In these experiments, total RNA extracted from human heart $(\mathrm{H})$ and human carotid artery (A) was used as positive control, whereas Jurkat cells $(\mathrm{J})$ were used as negative control (Figure 10). No detectable signal was observed with Jurkat cells $(\mathrm{J})$, although all cardiac lineage markers and endothelial markers were robustly detected in samples from the heart $(\mathrm{H})$ and artery $(\mathrm{A})$, suggesting true expression of the genes of interest. To further examine expression levels of cardiac proteins following differentiation, we performed ICG using cardiac lineage-specific antibodies anti-CD31, $\alpha$-SMA, $\alpha$-SA, and cTnI.
As it shown in Figure 10B and 10C, $>85 \%$ CSCs expressed c-kit antigen before differentiation, however, the c-kit signal disappeared on Day 35 after differentiation although c-kit mRNA could still be detected (Figure 10A). In contrast, in we did not find $\mathrm{CD}^{+} 1^{+}$(endothelial marker) and $\mathrm{cTnI}^{+}$(cardiac marker) cells in the $\mathrm{c}-\mathrm{kit}^{+}$population before differentiation by ICC, but a small percentage of $\alpha-\mathrm{SMA}^{+}(4.1 \pm 0.4 \%)$ and cardiac $\alpha-\mathrm{SA}^{+}(9.3 \pm 2.0 \%)$ was detected (Figure 10, $\mathrm{n}=3$ patients). Following cardiac differentiation, these markers were dramatically increased on Day 35. The $\mathrm{CD}^{+} 1^{+}$cells increased from 0 to $10.3 \pm 1.2 \%, \alpha-$ $\mathrm{SMA}^{+}$cells from $4.1 \pm 0.4 \%$ to $16.7 \pm 3.5 \%, \alpha-\mathrm{SA}^{+}$cells from $9.3 \pm 2.0 \%$ to $70.7 \pm 6.2 \%$, and $\mathrm{cTnI}^{+}$cells from $0 \%$ to $71.4 \pm 6.9 \%$ $(\mathrm{n}=3$ patients in each group, $p<0.05$ or $p<0.001$, Figure 10$)$. These data suggest that the pre-committed c-kit ${ }^{+} / \mathrm{Lin}^{-}$CSCs are capable of differentiating into three cardiac lineages after induction by $5-\mathrm{AZ}$. Although a majority of the c-kit ${ }^{+}$(about $70 \%$ ) tend to become cardiomyocytes, some cells (about 30\%) differentiate into smooth muscle and endothelial cells.

\section{Discussion}

The results of the current study show that both tissue sections and cells freshly isolated from human atrial appendages specimens contain a small population of $\mathrm{c}-\mathrm{kit}^{+} / \mathrm{Lin}^{-}$cells. Without further purification, a gradual increase in the percentage of $\mathrm{c}-\mathrm{kit}^{+}$cells was observed, which increased to $40 \%$. The percentage of c-kit ${ }^{+}$cells did not increase further upon Lin-depletion following c-kit MACS. 

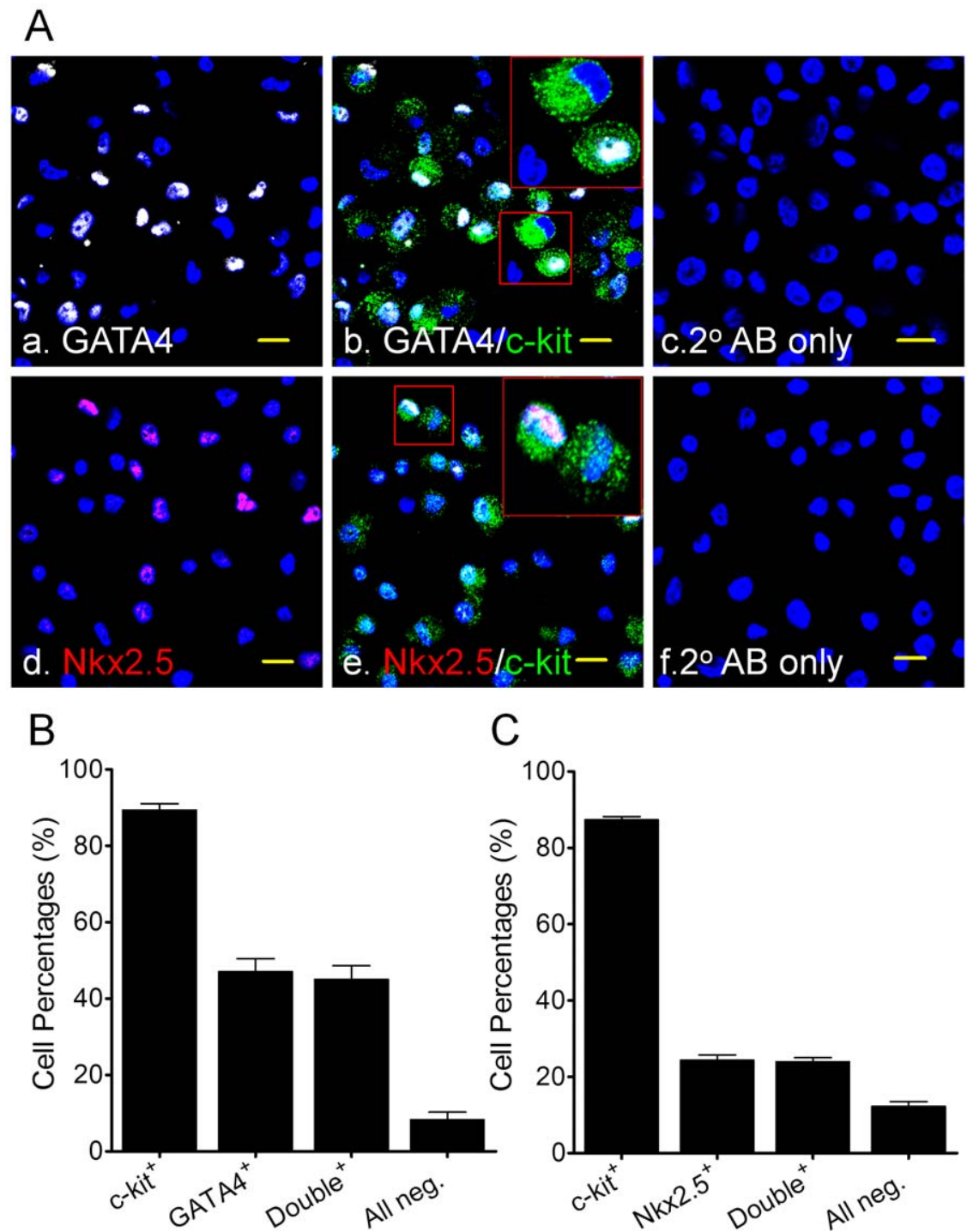

Figure 9. Early cardiac transcription factor staining. Panel A showed the representative Confocal images of GATA4 (upper row, white) and Nkx2.5 (lower row, red) antibody staining on human c-kit ${ }^{+}$CSCs. Insets in b and e showed the enlarged overlap images of GATA4 ${ }^{+} / \mathrm{c}-\mathrm{kit}^{+}$and Nkx2.5 $5^{+} /$ c-kit ${ }^{+}$cells, respectively. The secondary antibody $\left(2^{\circ} \mathrm{AB}\right)$ conjugated with FITC or APC were used as negative control. c-kit was stained in green (FITC) and nuclei were stained in blue (DAPI). Scale bars $=20 \mu \mathrm{m}$. Panel B and C showed the Mean \pm SEM of GATA4 and Nkx2.5 ICC data from three patients, respectively, where single positive $\left(\mathrm{c}-\mathrm{kit}^{+}\right)$and double positive $\left(\mathrm{c}-\mathrm{kit}^{+} / \mathrm{GATA} 4^{+}\right.$, left panel; $\mathrm{c}-\mathrm{kit}^{+} / \mathrm{Nkx} 2.5^{+}$, right panel) cells were counted and percentages were plotted.

doi:10.1371/journal.pone.0027719.g009

Nevertheless, c-kit expression was stable during long-term culture up to passage 10. Moreover after c-kit MACS, $\mathrm{c}-\mathrm{kit}^{+} / \mathrm{Lin}^{-}$cells were negative for hematopoietic stem cells (CD34, CD45, CD133) and Lin markers, however, in a few patients cells positive for endothelial marker (KDR/CD31) were observed. Lin-dep procedure seemed unnecessary for further enrichment of c-kit ${ }^{+}$cells. No contamination from fibroblasts and mast cells was found. Importantly, c-kit ${ }^{+}$CSCs could differentiate into three cardiac lineages. A major of these cells were transformed into cardiomyocytes, while a small population differentiated into smooth muscle and endothelial cells. Although several laboratories have published studies describing the isolation and characterization of human $\mathrm{c}-\mathrm{kit}^{+} / \mathrm{Lin}^{-}$CSCs $[9,12,22,23,47]$ the stability of the stem cell characteristics of the population, contamination from hematopoietic stem cells or differentiation into cells of cardiovascular lineage has not been clearly established and therefore remain controversial $[34,45,48]$.

\section{Stable expression of c-kit in CSCs}

Recent evidence supports the view that the adult heart contains a discrete population of self-renewing stem cells $[1,36,49,50]$. Using different stem cell markers and isolation methods, at least

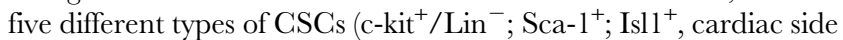
population $/ \mathrm{Abcg} 2^{+} / \mathrm{MDR}^{+}$cells, and cardiospheres/c-kit ${ }^{+} / \mathrm{Sca}-$ $1^{+} / \mathrm{Flk}^{+}$) have been described [13,21]. Among these, the c-kit ${ }^{+} /$ $\mathrm{Lin}^{-}$population has been most widely studied. These cells demonstrate typical stem cell properties of self-renewing, clonogenesis, and multipotency with the ability to differentiate into cardiomyocytes, smooth muscle cells, and endothelial cells in vitro [1]. Although in some in vivo studies c-kit ${ }^{+} / \mathrm{Lin}^{-}$cells have shown beneficial results against cardiac remodeling after $\mathrm{MI}$, in others no effect or only marginally significant effects were observed [13,5154]. This inconsistency may be related to variations in procedures used for cell isolation and transplantation and the lack of a 
A

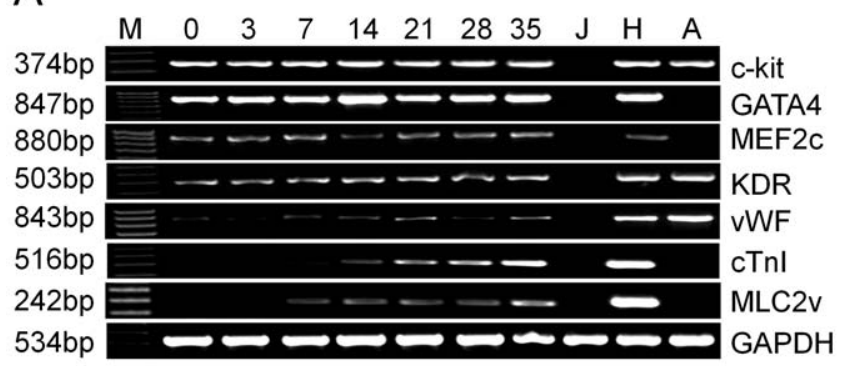

C

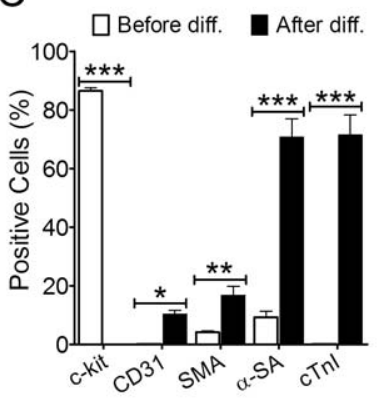

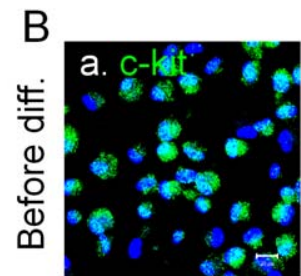

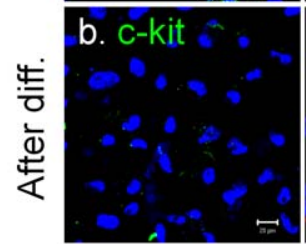

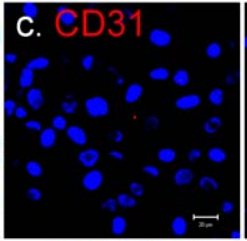

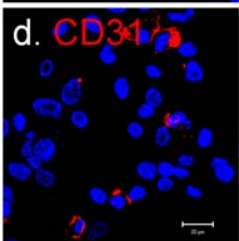

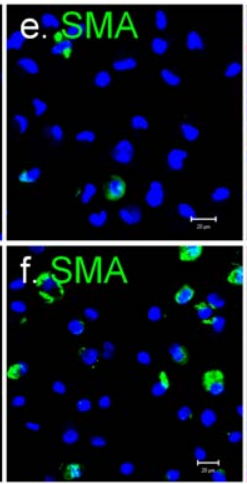
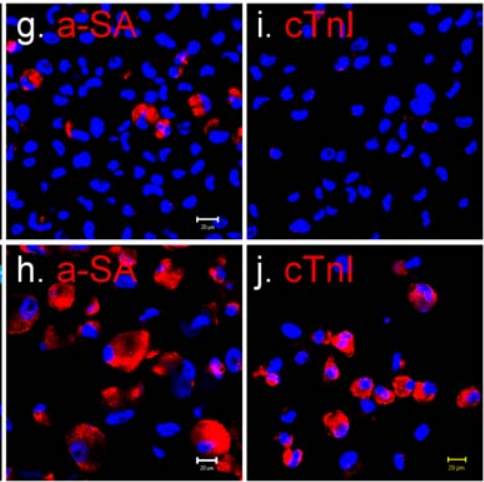

Figure 10. Cardiac lineage differentiation induced by $\mathbf{5}$-azacytidine. Panel A displayed the representative RT-PCR data of cardiac lineage genes (cardiac genes: GATA4, MEF2c, CTnl, and MLC2v; endothelial genes: KDR and vWF) before (Day 0) and after differentiation (Day 3, 7, 14, 21, 28, and 35). Stem cell marker (c-kit) and GAPDH were also included as a control. Total RNA of human Jurkat cell (J), human Heart (H) and human carotid artery (A) were used as negative and positive controls, respectively. DNA molecular marker (M) was shown the first column as $M$ (bp). Panel B showed the representative Confocal images of c-kit (green-FITC), CD31 (red-APC), $\alpha$-SMA (green-FITC), $\alpha$-SA (red-APC), and cTnl (red-APC) before (upper) and after (lower) differentiation. Nuclei were stained in blue (DAPI). Scale bars $=20 \mu \mathrm{m}$. Panel C showed the MEAN \pm SEM of quantitative ICC data from three patients ( $\mathrm{n}=3$ patients). ${ }^{*}: p<0.05,{ }^{* *}: p<: 0.01,{ }^{* * *}: p<0.001$. Each data was compared with its control levels (before differentiation). doi:10.1371/journal.pone.0027719.g010

consistent protocol for preserving the stemness of these cells and minimizing contamination by other cells.

In normal human heart, c-kit ${ }^{+}$CSCis reside in discrete stem cell niches, but their overall abundance in the heart is rather low. Although some investigators have attempted to quantify the percentage of $\mathrm{c}^{-\mathrm{kit}^{+}}$cells in whole heart [1], it is difficult to obtain accurate estimates based on quantification of heart section or freshly isolated cells. Quantification of c-kit $^{+}$cells by counting every single cell (including c-kit ${ }^{+}$cells) in the entire human heart is tedious and often not feasible. On the other hand, counting these cells in fresh cell isolates is confounded by the presence of a large amount of dead cells, cell debris and clumps, making it difficult to get an accurate estimate of the abundance of the c-kit ${ }^{+}$population either by flow cytometry or immunestaining. Nevertheless, our histological analysis of the atrial appendage indicated that the abundance of these cells in the human hearts is similar to that reported for the rat heart [12]. Because the right atrium is believed to be the highest levels of these cells [22,23], it is likely the percentage of c-kit ${ }^{+}$in other parts of heart might be even lower. Thus, expansion of c-kit ${ }^{+}$cells from samples of the ventricle or the septum is likely to be more difficult than from atrial tissue and would require a longer time to allow the cells to grow to numbers required for clinical transplantation.

The impact of long-term cell culture on the enrichment of c-kit ${ }^{+}$ cells before purification has not been systemically assessed either. The published data are variable. Itzhaki-Alfia et al found that the dissociated human right-atrium generated $24 \pm 2.5 \%$ of c-kit ${ }^{+}$ before ${\mathrm{c}-\mathrm{kit}^{+}}^{+}$cell purification [22]., whereas Messina et al have reported that in cardiospheres-derived stem cells of murine heart there were $\sim 30 \%$ c-kit $^{+}$cells at Day 6 vs $10 \%$ at Day 0 after platting [9]; where Davis et al demonstrated that in rat heart, there were $\sim 12 \%$ c-kit $^{+}$cells on Day 21 vs $5 \%$ at Day 7 after culture [55]. We found that c-kit ${ }^{+}$cells were gradually increased from very lower level in freshly isolated preparation up to $10 \%$ to $40 \%$ within two passage (about ten days) before c-kit MACS procedure. During the long-term culture (about 40-50 days), the percentage of c-kit ${ }^{+}$cells remained stable at about $30-40 \%$ without any purification processes. The underlying mechanisms for this increase in c-kit ${ }^{+}$cells remain unknown, but the expansion of these cells probably depends upon natural selection exerted by culture medium, which may favor or facilitate the proliferation of c-kit $^{+}$CSCs over other cell types [9,56-58]. However despite of such selection, the abundance of $\mathrm{c}^{-\mathrm{kit}^{+}}{ }^{+}$cells did not exceed $80 \%$ unless c-kit MACS step was applied. Following this procedure, the purified $\mathrm{c}-\mathrm{kit}^{+}$cell population were be able to maintain its c-kit expression at a high level for more than month thus providing a uniform and stable population appropriate for clinical use.

\section{Contaminations of other cells types}

Following the initial study reporting $\mathrm{c}^{-\mathrm{kit}^{+}}{ }^{+} \mathrm{CSC}$ s in the rat heart [1], several investigators have identified CSCs from hearts of various species, including mice [9,59], rats [60], dogs [61], pigs [62], and humans [12,36]. These studies were focused mainly on

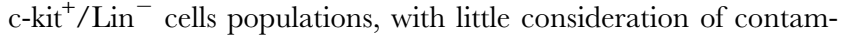
ination from other cell types such as the mast cells, which are also

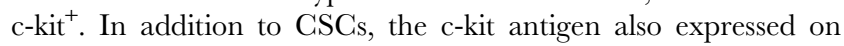
other tissues including hematopoietic stem cells from the bone marrow [63,64], cardiac mast cells [33,34], melanocytes [65], 
interstitial cells of Cajal, prostate stem cells [66], and others [67]. Indeed within the population of cells isolated from the atrial appendage using enzymatic dissociation, we did find small percents of contaminating cell population expressing Lin, the fibroblast antigen, KDR or CD31. Although most of contaminated cells could be excluded using c-kit MACS, but in many cases the purity of $\mathrm{c}^{-k i t^{+}}$could not reach $100 \%$, suggesting that other un-identified cell types, not identified by current approaches and cellular markers, may be present in the preparation. Nevertheless, we confirmed that a majority $(>80 \%)$ of sorted CSCs were c-kit ${ }^{+}$ and the rest of contaminated cells (if any) are not mast cell, fibroblasts, hematopoietic stem cells, and/or lineage cells. These data are consistent with other published studies [1,12,13, $23,36,47]$. However, Zhou et al have recently reported that $85 \%$

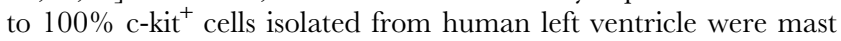
cells that displayed a weak or moderate signal for CD45, but were strongly positive for mast-cell markers such as Tryptase, Toluidine blue and Thionine [34]. In contrast, we found that c-kit ${ }^{+}$cells were negative for mast cell marker even before c-kit purification and that these cells were also CD45 negative (as confirmed by flow cytometry and ICC using cells from at least three different patients). This disparity may be due to several reasons including the use of different experimental conditions, methods, patient, and especially tissue used to isolate the cells. For instance, Zhou used biopsy from left ventricle tissues v.s. the atrial appendages used in the present study. Another potential reason for undetectable mast cells in the present study may be due to non-adherent property of mast cells, which were probably washed away when medium was changed next day. It is known that the optimal methods are critical for the successful identification of true cardiac mast cells [68], hence the use of culture conditions described here should preclude contamination from mast cells and facilitate high yield recovery of a uniform population of $\mathrm{c}^{-\mathrm{kit}^{+}}$CSCs.

\section{Cardiac differentiation potential}

A variety of CSCs isolated from humans and experimental models [13] have been differentiated into cardiovascular lineages using different culture condition, including co-culture with mature or neonatal cardiomyocytes $[5,8,69,70]$, induction with 5-azacytidine [4], Oxytocin [3], or Dexamethasone [1,12,36]. Although these $\mathrm{c}-\mathrm{kit}^{+} / \mathrm{Lin}^{-} \mathrm{CSC}$ s have been widely studied, attempts to differentiate these cells in vitro have led to inconsistent results. It has been previously reported that in intact tissues sections from human hearts, the percentage of c-kit ${ }^{+}$cells in right atrial tissue decreases from $8.9 \pm 0.4 \%$ in neonates to $6.4 \pm 0.2 \%$ to $3.2 \pm 0.1 \%$ in children from 2 to 13 years. Resident CSCs have been found to be most abundant in hearts of neonates [23]. However in adult human heart, the number of c-kit ${ }^{+}$cells in even lower $0.01 \%$ [12], which was comparable to our estimates presented here. Because c$\mathrm{kit}^{+} / \mathrm{Lin}^{-}$cells are pre-committed resident CSCs, it is likely that they exist in heart in various stages of development and therefore they express cardiac lineage markers. Published data support this hypothesis. In human heart during early development c-kit ${ }^{+}$and $\mathrm{Nkx} 2.5^{+}$were co-expressed in some CSGs with relative lower levels that range from $2.9 \pm 0.1 \%$ in neonates, $1.5 \pm 0.1 \%$ in infants to $1.0 \pm 0.1 \%$ in children 2 to 13 years [23]. In adult hearts, however, several different populations of stem cells committed to the cardiac lineage have been identified. These include (a) precommitted cardiomyocytes co-expressing $\mathrm{c}^{-\mathrm{kit}^{+}} / \mathrm{Nkx} 2.5^{+},{\mathrm{c}-\mathrm{kit}^{+} /}^{+}$

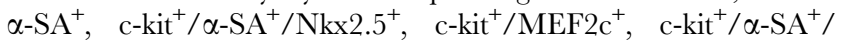
$\mathrm{MEF} 2 \mathrm{c}^{+}$in CSG niches of tissue sections of rat [1], mouse [71], and human hearts [12,72]; (b) Pre-committed endothelial

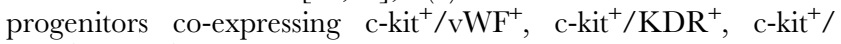
$\mathrm{vWF}^{+} / \mathrm{KDR}^{+}$; and (c) Pre-committed smooth muscle cells co- expressing $\mathrm{c}-\mathrm{kit}^{+} / \mathrm{KDR}^{+} / \alpha-\mathrm{SMA}^{+}$in vascular niches of human hearts $[1,12,72]$. However, due to a variety of technical reasons, the actual number of each type of pre-committed CSCs within the entire heart has not been reported [12], although their abundance has been presumed to be low. Nevertheless, previous published data as well as our present data suggests that several types of precommitted CSCs at various differentiation stages exist in adult hearts and therefore it is possible to obtain or identify these cells after dissociation.

In vitro single cell preparations of cardiac cells provide an alternative approach for identifying pre-committed CSCs with specific antibodies including anti-c-kit and/or other cardiac lineage markers or by using the more sensitive RT-PCR technique to detect cardiac genes expression. Previous studies from several laboratories have reported variable levels of $\mathrm{c}^{-\mathrm{kit}^{+}}$expressions in cultured cells before purification and differentiation. Beltrami et al [1] found that the percentage of $\mathrm{c}^{-\mathrm{kit}^{+}}$cell was $7-10 \%$ in cells isolated from the rat heart; but in cells isolated from the adult human right atrium, nearly 20 to $40 \%$ of the cells [12] [22] were found to be c-kit ${ }^{+}$. This estimate is similar to our finding that $10-$ $40 \%$ of the cells in isolate were c-kit ${ }^{+}$before purification and differentiation. Characterization of early myogenic transcription factors of CSCs isolated from human heart has shown that $60 \pm 6 \%$ [22] or $59 \pm 14 \%$ [12] of the cells were GATA $4^{+}$whereas $60 \pm 11 \%$ [22] of the cells were also positive for the late cardiac marker $(\alpha-\mathrm{SA})$. In agreement with these results we found that nearly $50 \%$ of cells were positive for both c-kit and GATA4. However, the abundance of $\mathrm{c}-\mathrm{kit}^{+}$cells expressing Nkx2.5, $\alpha$ SMA, and $\alpha$-SA was low. Based on cardiac lineage makers and their capacity for differentiation, D'Amario et al have suggested that ${\mathrm{c}-\mathrm{kit}^{+}}^{+}$CSCs could be classified into two groups - the "myogenic CSCs" (mCSCs) and the "vasculogenic CSCs" (vCSCs) [36]. This classification was based on their data showing that most of the mCSCs became cardiomyocytes, whereas the vCSCs differentiate primarily into endothelial and smooth muscle cells [36]. However, in their study, before differentiation, the c-kit ${ }^{+}$ cell population was negative for the cardiovascular markers GATA4, Nkx2.5, MEF2c, $\alpha$-SA, $\alpha$-SMA, CD31, and TGF- $\beta-1 \mathrm{R}$ and only a small percent of cells $(3.3 \pm 1.1 \%)$ were positive for $\mathrm{KDR}$, as determined by flow cytometry $[12,36,72]$. This is inconsistent with the previous study using the same technique [12] or the results obtained by other investigators $[22,23]$ including our data presented here. Hence, the extent of differentiation of human CSCs in situ or before in vitro differentiation remains unclear.

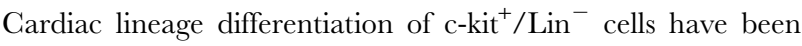
studied in various laboratories using either chemical reagents (such as Dexamethasone) or co-culture with neonatal or matured cardiomyocytes [13]. It has been reported that treatment with Dexamethasone results in the appearance of cardiac markers GATA4, Nkx2.5, MEF2c, and cardiac $\alpha$-SA) in $~ 50 \%$ of mCSCs, whereas $\sim 10-15 \%$ of the cells show smooth muscle and endothelial markers (GATA6, $\alpha$-SMA, CD31, and vWF) after differentiation [36]. On the other hand, $\sim 40 \%-50 \%$ vCSCs became positive for smooth muscle and endothelial markers (GATA6, $\alpha$-SMA, CD31, and vWF), and small percents of them $(\sim 10-15 \%)$ showed positive for cardiac markers (GATA4, Nkx2.5, MEF2c, and $\alpha-\mathrm{SA})$ after differentiation [36]. In our study upon treatment with 5-AZ [37], we observed that a majority $(\sim 70 \%)$ of c-kit $^{+}$cells differentiated into cardiomyocytes, but small percent $(\sim 30 \%)$ of c-kit ${ }^{+}$cells became smooth muscle and endothelial cells, demonstrating more efficient cardiomyocyte differentiation has been reported than before [36].

In conclusion, we have systemically and quantitatively characterized $\mathrm{c}-\mathrm{kit}^{+} / \mathrm{Lin}^{-} \mathrm{CSC}$ s isolated from human atrial appendages. 
We have developed appropriate procedures and protocols for maintaining purified c-kit ${ }^{+}$cells. The cells maintained in culture stably expressed high percentage of c-kit antigen without contamination by other cells types except for in a few cases by $\mathrm{CD} 1^{+}$and $\mathrm{KDR}^{+}$cells. Upon induction of differentiation, GSCs were able to become cardiomyocytes, smooth muscle and endothelial cells. We conclude that by using the simplified enzymatic dissociation method, a large number, but higher percent of relative pure $\mathrm{c}-\mathrm{kit}^{+} / \mathrm{Lin}^{-} \mathrm{CSG}$ could be obtained from atrial appendages specimens within $\sim 4$ weeks following c-kit MACS without Lin-dep. This simple, but cost-effective approach could be used to obtain sufficient numbers of stable c-kit ${ }^{+}$cells for transplantation into patients with heart failure and myocardial infarct.

\section{References}

1. Beltrami AP, Barlucchi L, Torella D, Baker M, Limana F, et al. (2003) Adult cardiac stem cells are multipotent and support myocardial regeneration. Cell 114: 763-776.

2. Matsuura K, Yoshioka S, Tosha T, Hori H, Ishimori K, et al. (2005) Structural diversities of active site in clinical azole-bound forms between sterol 14alphademethylases (CYP51s) from human and Mycobacterium tuberculosis. J Biol Chem 280: 9088-9096.

3. Matsuura K, Nagai T, Nishigaki N, Oyama T, Nishi J, et al. (2004) Adult cardiac Sca-1-positive cells differentiate into beating cardiomyocytes. J Biol Chem 279: 11384-11391.

4. Oh H, Bradfute SB, Gallardo TD, Nakamura T, Gaussin V, et al. (2003) Cardiac progenitor cells from adult myocardium: homing, differentiation, and fusion after infarction. Proc Natl Acad Sci U S A 100: 12313-12318.

5. Laugwitz KL, Moretti A, Lam J, Gruber P, Chen Y, et al. (2005) Postnatal isl1+ cardioblasts enter fully differentiated cardiomyocyte lineages. Nature 433: 647-653.

6. Bu L, Jiang X, Martin-Puig S, Caron L, Zhu S, et al. (2009) Human ISL1 heart progenitors generate diverse multipotent cardiovascular cell lineages. Nature 460: $113-117$.

7. Pfister O, Mouquet F, Jain M, Summer R, Helmes M, et al. (2005) CD31- but Not CD31+ cardiac side population cells exhibit functional cardiomyogenic differentiation. Circ Res 97: 52-61.

8. Hierlihy AM, Seale P, Lobe CG, Rudnicki MA, Megeney LA (2002) The postnatal heart contains a myocardial stem cell population. FEBS Lett 530: 239-243.

9. Messina E, De AL, Frati G, Morrone S, Chimenti S, et al. (2004) Isolation and expansion of adult cardiac stem cells from human and murine heart. Circ Res 95: 911-921.

10. Johnston PV, Sasano T, Mills K, Evers R, Lee ST, et al. (2009) Engraftment, differentiation, and functional benefits of autologous cardiosphere-derived cells in porcine ischemic cardiomyopathy. Circulation 120: 1075-1083.

11. Li TS, Cheng K, Lee ST, Matsushita S, Davis D, et al. (2010) Cardiospheres recapitulate a niche-like microenvironment rich in stemness and cell-matrix interactions, rationalizing their enhanced functional potency for myocardial repair. Stem Cells 28: 2088-2098.

12. Bearzi G, Rota M, Hosoda T, Tillmanns J, Nascimbene A, et al. (2007) Human cardiac stem cells. Proc Natl Acad Sci U S A 104: 14068-14073.

13. Barile L, Chimenti I, Gaetani R, Forte E, Miraldi F, et al. (2007) Cardiac stem cells: isolation, expansion and experimental use for myocardial regeneration. Nat Clin Pract Cardiovasc Med 4 Suppl 1: S9-S14.

14. Bolli P, Chaudhry HW (2010) Molecular physiology of cardiac regeneration. Ann N Y Acad Sci 1211: 113-126.

15. Bollini S, Smart N, Riley PR (2011) Resident cardiac progenitor cells: At the heart of regeneration. J Mol Cell Cardiol 50: 296-303.

16. Kuhn EN, Wu SM (2010) Origin of cardiac progenitor cells in the developing and postnatal heart. J Cell Physiol 225: 321-325.

17. Cai CL, Martin JC, Sun Y, Cui L, Wang L, et al. (2008) A myocardial lineage derives from Tbx18 epicardial cells. Nature 454: 104-108.

18. Kostin S, Popescu LM (2009) A distinct type of cell in myocardium: interstitial Cajal-like cells (ICLCs). J Cell Mol Med 13: 295-308.

19. Gittenberger-de Groot AC, Winter EM, Poelmann RE (2010) Epicardiumderived cells (EPDCs) in development, cardiac disease and repair of ischemia. J Cell Mol Med 14: 1056-1060.

20. Ellison GM, Galuppo V, Vicinanza C, Aquila I, Waring CD, et al. (2010) Cardiac stem and progenitor cell identification: different markers for the same cell? Front Biosci (Schol Ed) 2: 641-652.

21. Bollini S, Smart N, Riley PR (2010) Resident Cardiac Progenitor Cells: At the Heart of Regeneration. J Mol Cell Cardiol 50: 296-303.

22. Itzhaki-Alfia A, Leor J, Raanani E, Sternik L, Spiegelstein D, et al. (2009) Patient characteristics and cell source determine the number of isolated human cardiac progenitor cells. Circulation 120: 2559-2566.

\section{Acknowledgments}

We are grateful to Dr. James McCracken and Dr. Gregg Rokosh for the technical assistance in flow cytometry and usage of their lab equipments. We also want to thank Dr. Gregg Rokosh, Dr. Qian-Hong Li, Dr. Yuro Guo, Dr. Xian-Liang Tang, and Dr. Kyung Hong for their critical and valuable discussions of original data. We are greatly indebted to Jewish Hospital at Louisville of Kentucky for providing the waste specimens of right atrial appendage during open heart surgery.

\section{Author Contributions}

Conceived and designed the experiments: JQH DMV. Performed the experiments: DMV JQH GH AC. Analyzed the data: JQH DMV. Contributed reagents/materials/analysis tools: JQH DMV GH AC. Wrote the paper: JQH AB RB.

23. Mishra R, Vijayan K, Colletti EJ, Harrington DA, Matthiesen TS, et al. (2011) Characterization and functionality of cardiac progenitor cells in congenital heart patients. Circulation 123: 364-373.

24. Smith RR, Barile L, Cho HC, Leppo MK, Hare JM, et al. (2007) Regenerative potential of cardiosphere-derived cells expanded from percutaneous endomyocardial biopsy specimens. Circulation 115: 896-908.

25. Chimenti I, Gaetani R, Barile L, Frati G, Messina E, et al. (2009) c-kit cardiac progenitor cells: what is their potential? Proc Natl Acad Sci U S A 106: E78.

26. Tang XL, Rokosh G, Sanganalmath SK, Yuan F, Sato H, et al. (2010) Intracoronary administration of cardiac progenitor cells alleviates left ventricular dysfunction in rats with a 30-day-old infarction. Circulation 121: 293-305.

27. Lovell MJ, Mathur A (2010) Cardiac stem cell therapy: progress from the bench to bedside. Heart 96: 1531-1537.

28. Guan K, Hasenfuss G (2007) Do stem cells in the heart truly differentiate into cardiomyocytes? J Mol Cell Cardiol 43: 377-387.

29. Davis DR, Zhang Y, Smith RR, Cheng K, Terrovitis J, et al. (2009) Validation of the cardiosphere method to culture cardiac progenitor cells from myocardial tissue. PLoS One 4: e7195-e7122.

30. Andersen DC, Andersen P, Schneider M, Jensen HB, Sheikh SP (2009) Murine "cardiospheres" are not a source of stem cells with cardiomyogenic potential. Stem Cells 27: 1571-1581.

31. Katayama N, Shih JP, Nishikawa S, Kina T, Clark SC, et al. (1993) Stagespecific expression of c-kit protein by murine hematopoietic progenitors. Blood 82: $2353-2360$

32. Sandstedt J, Jonsson M, Lindahl A, Jeppsson A, Asp J (2010) C-kit+ CD45- cells found in the adult human heart represent a population of endothelial progenitor cells. Basic Res Cardiol 105: 545-556.

33. Sperr WR, Bankl HC, Mundigler G, Klappacher G, Grossschmidt K, et al. (1994) The human cardiac mast cell: localization, isolation, phenotype, and functional characterization. Blood 84: 3876-3884.

34. Zhou Y, Pan P, Yao L, Su M, He P, et al. (2010) CD117-positive cells of the heart: progenitor cells or mast cells? J Histochem Cytochem 58: 309-316.

35. Boni A, Urbanek K, Nascimbene A, Hosoda T, Zheng H, et al. (2008) Notch1 regulates the fate of cardiac progenitor cells. Proc Natl Acad Sci U S A 105: $15529-15534$

36. D'Amario D, Fiorini C, Campbell PM, Goichberg P, Sanada F, et al. (2011) Functionally competent cardiac stem cells can be isolated from endomyocardial biopsies of patients with advanced cardiomyopathies. Circ Res 108: 857-861.

37. Smits AM, van VP, Metz CH, Korfage T, Sluijter JP, et al. (2009) Human cardiomyocyte progenitor cells differentiate into functional mature cardiomyocytes: an in vitro model for studying human cardiac physiology and pathophysiology. Nat Protoc 4: 232-243.

38. Kondo M, Weissman IL, Akashi K (1997) Identification of clonogenic common lymphoid progenitors in mouse bone marrow. Cell 91: 661-672.

39. Fajtova M, Babusikova O (2010) Immunophenotype characterization of hematopoietic stem cells, progenitor cells restricted to myeloid lineage and their leukemia counterparts. Neoplasma 57: 392-400.

40. Zeisberg EM, Kalluri R (2010) Origins of cardiac fibroblasts. Circ Res 107: $1304-1312$

41. Singer KH, Scearce RM, Tuck DT, Whichard LP, Denning SM, et al. (1989) Removal of fibroblasts from human epithelial cell cultures with use of a complement fixing monoclonal antibody reactive with human fibroblasts and monocytes/macrophages. J Invest Dermatol 92: 166-170.

42. Esterre P, Melin M, Serrar M, Grimaud JA (1992) New specific markers of human and mouse fibroblasts. Cell Mol Biol 38: 297-301.

43. Ronnov-Jessen L, Celis JE, Van DB, Petersen OW (1992) A fibroblast-associated antigen: characterization in fibroblasts and immunoreactivity in smooth muscle differentiated stromal cells. J Histochem Cytochem 40: 475-486.

44. Strutz F, Okada H, Lo CW, Danoff T, Carone RL, et al. (1995) Identification and characterization of a fibroblast marker: FSP1. J Cell Biol 130: 393-405.

45. Genovese A, Rossi FW, Spadaro G, Galdiero MR, Marone G (2010) Human cardiac mast cells in anaphylaxis. Chem Immunol Allergy 95: 98-109. 
46. Reid AC, Silver RB, Levi R (2007) Renin: at the heart of the mast cell. Immunol Rev 217: 123-140.

47. van VP, Sluijter JP, Doevendans PA, Goumans MJ (2007) Isolation and expansion of resident cardiac progenitor cells. Expert Rev Cardiovasc Ther 5: 33-43.

48. Camelliti P, Borg TK, Kohl P (2005) Structural and functional characterisation of cardiac fibroblasts. Cardiovasc Res 65: 40-51.

49. Anversa P, Kajstura J, Leri A, Bolli R (2006) Life and death of cardiac stem cells: a paradigm shift in cardiac biology. Circulation 113: 1451-1463.

50. D'Alessandro DA, Kajstura J, Hosoda T, Gatti A, Bello R, et al. (2009) Progenitor cells from the explanted heart generate immunocompatible myocardium within the transplanted donor heart. Circ Res 105: 1128-1140.

51. Barile L, Messina E, Giacomello A, Marban E (2007) Endogenous cardiac stem cells. Prog Cardiovasc Dis 50: 31-48.

52. Smith RR, Barile L, Messina E, Marban E (2008) Stem cells in the heart: what's the buzz all about? Part 2: Arrhythmic risks and clinical studies. Heart Rhythm 5: 880-887.

53. Smith RR, Barile L, Messina E, Marban E (2008) Stem cells in the heart: what's the buzz all about?-Part 1: preclinical considerations. Heart Rhythm 5: 749-757.

54. Wu JC, Abraham MR, Kraitchman DL (2010) Current perspectives on imaging cardiac stem cell therapy. J Nucl Med 51 Suppl 1: 128S-136S.

55. Davis DR, Kizana E, Terrovitis J, Barth AS, Zhang Y, et al. (2010) Isolation and expansion of functionally-competent cardiac progenitor cells directly from heart biopsies. J Mol Cell Cardiol 49: 312-321.

56. Muta K, Krantz SB, Bondurant MC, Dai CH (1995) Stem cell factor retards differentiation of normal human erythroid progenitor cells while stimulating proliferation. Blood 86: 572-580.

57. Kashiwakura I, Takahashi TA (2003) Basic fibroblast growth factor-stimulated ex vivo expansion of haematopoietic progenitor cells from human placental and umbilical cord blood. Br J Haematol 122: 479-488.

58. Yeoh JS, de HG (2007) Fibroblast growth factors as regulators of stem cell selfrenewal and aging. Mech Ageing Dev 128: 17-24.

59. Bailey B, Izarra A, Alvarez R, Fischer KM, Cottage CT, et al. (2009) Cardiac stem cell genetic engineering using the alphaMHC promoter. Regen Med 4: 823-833.

60. Cottage CT, Bailey B, Fischer KM, Avitable D, Collins B, et al. (2010) Cardiac progenitor cell cycling stimulated by pim-1 kinase. Circ Res 106: 891-901.
61. Linke A, Muller P, Nurzynska D, Casarsa C, Torella D, et al. (2005) Stem cells in the dog heart are self-renewing, clonogenic, and multipotent and regenerate infarcted myocardium, improving cardiac function. Proc Natl Acad Sci U S A 102: 8966-8971.

62. Hatzistergos KE, Quevedo H, Oskouei BN, Hu Q Feigenbaum GS, et al. (2010) Bone Marrow Mesenchymal Stem Cells Stimulate Cardiac Stem Cell Proliferation and Differentiation. Circ Res 107: 913-922.

63. Orlic D, Fischer R, Nishikawa S, Nienhuis AW, Bodine DM (1993) Purification and characterization of heterogeneous pluripotent hematopoietic stem cell populations expressing high levels of c-kit receptor. Blood 82: 762-770.

64. Orlic D, Kajstura J, Chimenti S, Bodine DM, Leri A, et al. (2001) Transplanted adult bone marrow cells repair myocardial infarcts in mice. Ann N Y Acad Sci 938: $221-229$.

65. Monsel G, Ortonne N, Bagot M, Bensussan A, Dumaz N (2010) c-Kit mutants require hypoxia-inducible factor lalpha to transform melanocytes. Oncogene 29: 227-236.

66. Leong KG, Wang BE, Johnson L, Gao WQ (2008) Generation of a prostate from a single adult stem cell. Nature 456: 804-808.

67. Miettinen M, Lasota J (2005) KIT (CD117): a review on expression in normal and neoplastic tissues, and mutations and their clinicopathologic correlation. Appl Immunohistochem Mol Morphol 13: 205-220.

68. Meuser-Batista M, Correa JR, Soares MJ, Henriques-Pons A (2008) Isolation of cardiac mast cells in experimental Trypanosoma cruzi infection. Tissue Cell 40: 309-316.

69. Mouquet F, Pfister O, Jain M, Oikonomopoulos A, Ngoy S, et al. (2005) Restoration of cardiac progenitor cells after myocardial infarction by selfproliferation and selective homing of bone marrow-derived stem cells. Circ Res 97: 1090-1092.

70. Pfister O, Oikonomopoulos A, Sereti KI, Sohn RL, Cullen D, et al. (2008) Role of the ATP-binding cassette transporter Abcg2 in the phenotype and function of cardiac side population cells. Circ Res 103: 825-835.

71. Rota M, Lecapitaine N, Hosoda T, Boni A, De AA, et al. (2006) Diabetes promotes cardiac stem cell aging and heart failure, which are prevented by deletion of the p66shc gene. Circ Res 99: 42-52.

72. Bearzi G, Leri A, Lo MF, Rota M, Gonzalez A, et al. (2009) Identification of a coronary vascular progenitor cell in the human heart. Proc Natl Acad Sci U S A 106: $15885-15890$ 